\title{
MODELANDO A PROPENSÃO AO ENDIVIDAMENTO: OS FATORES COMPORTAMENTAIS E SOCIOECONOMMICOS SÃO DETERMINANTES?*
}

\author{
ANI CAROLINE GRIGION POTRICH", KELMARA MENDES VIEIRA", DANIEL ARRUDA CORONEL \\ $\&$ REISOLI BENDER FILHO \\ UNIVERSIDADE FEDERAL DE SANTA MARIA (BRASIL)
}

Recibido/ Received/ Recebido: 26/03/2015 - Aceptado/ Accepted / Aprovado: 11/05/2016

\begin{abstract}
Resumo
O presente estudo analisa a influência dos fatores comportamentais e das variáveis socioeconômicas e demográficas sobre a propensão ao endividamento. Para tal fim realizou-se uma pesquisa a partir de 2.391 enquetes. Com base nas respostas utilizou-se a análise fatorial para validar os fatores de materialismo e compra compulsivas. Com a estimativa de um modelo Logit Multinomial analisou-se a influência destes fatores e das variáveis socioeconômicas e demográficas na propensão ao endividamento. Os principais resultados sugerem que, quanto pior for o comportamento materialista e de compra compulsivas do indivíduo, maior será a propensão a endividar-se. Da mesma forma, os que possuem dependentes, não possuem uma ocupação, têm menores níveis de idade, escolaridade e renda familiar são os que apresentam maior propensão ao endividamento. Entre as variáveis significativas destaca-se o fator de compras compulsivas, demonstrando que quanto maior o controle do comportamento de compras compulsivas do indivíduo, menor será sua propensão a endividar-se.

Palauras chave: Propensão ao endividamento; Logit multinomial; Compras compulsivas; Materialismo; Variáveis socioeconômicas e demográficas.
\end{abstract}

\section{MODELANDO LA PROPENSIÓN AL ENDEUDAMIENTO: ¿SON DETERMINANTES LOS FACTORES COMPORTAMENTALES Y SOCIOECONÓMICOS?}

\begin{abstract}
Resumen
El presente estudio analiza la influencia que tiene los factores comportamentales y las variables socioeconómicas y demográficas sobre la propensión al endeudamiento. Para tal fin se realizó una investigación a partir de 2.391 encuestas. Con base en las respuestas se utilizó el análisis factorial
\end{abstract}

\footnotetext{
Resultados do projeto vinculado ao Conselho Nacional de Desenvolvimento Científico e Tecnológico - CNPq, da Secretária de Políticas para as Mulheres da Presidência da República - SPM/PR e do Ministério de Desenvolvimento Agrário - MDA por meio do Edital CNPq no 32/2012.

* Doutoranda em Administração pela Universidade Federal de Santa Maria - PPGA/UFSM. Direção postal: Avenida Independência, n. 3751, Bairro Vista Alegre, CEP: 98.300-000 - Palmeira das Missões/RS (Brasil). Fone: (55) 3742-8821. E-mail: anipotrich@ gmail.com

*.. Doutora em Administração pela Universidade Federal do Rio Grande do Sul. Professora do Programa de Pós-Graduação em Administração da Universidade Federal de Santa Maria - PPGA/UFSM. E-mail: kelmara@terra.com.br

Doutor em Economia Aplicada pela Universidade Federal de Viçosa (UFV), mestre em Agronegócios pela Universidade Federal do Rio Grande do Sul (UFRGS), bacharel em Administração pela Universidade do Vale do Rio dos Sinos (UNISINOS) e em Ciências Econômicas pela UFSM. Professor Adjunto da Universidade Federal de Santa Maria (UFSM). E-mail: daniel.coronel@uol.com.br

Doutor em Economia Aplicada pela Universidade Federal de Viçosa. Professor do Programa de Pós-Graduação em Administração da Universidade Federal de Santa Maria - PPGA/UFSM. E-mail: reisolibender@yahoo.com.br
} 
para validar los factores de materialismo y compras compulsivas. Con la estimación de un modelo Logit Multinomial se analizó la influencia de estos factores y de las variables socioeconómicas y demográficas en la propensión al endeudamiento. Los principales resultados sugieren que, cuanto peor sea el comportamiento materialista y de compras compulsivas del individuo, mayor será la propensión a endeudarse. Así como que los que poseen dependientes, no poseen una ocupación, tienen menores niveles de edad, escolaridad y renta familiar son los que presentan mayor propensión al endeudamiento. Entre las variables significativas se destaca el factor de compras compulsivas, demostrando que cuanto mayor el control del comportamiento de compras compulsivas del individuo, menor será su propensión a endeudarse.

Palabras clave: Propensión al endeudamiento; Logit Multinomial; Compras compulsivas; Materialismo; Variables socioeconómicas y demográficas.

\title{
MODELING AN INDEBTEDNESS TENDENCY:ARE IMPORTANT BEHAVIORAL AND SOCIOECONOMIC FACTORS?
}

\begin{abstract}
This study analyzes the influence of behavioral factors and socioeconomic and demographic variables on the tendency to debt. For this purpose an investigation was conducted from 2,391 surveys. Based on the answers factor analysis was used to validate the factors of materialism and compulsive buying. With the estimation of a multinomial logit model the influence of these factors and socioeconomic and demographic in the propensity to debt variables was analyzed. The main results suggest that the poorer materialistic and compulsive shopping behavior of the individual, the greater the propensity to debt. And those with dependents, do not have an occupation, have lower levels of age, education and family income are those with greater propensity to debt. Among the significant variables a Compulsive shopping factor is highlighted, showing that the greater the control of the compulsive shopping behavior of the individual, the lower their propensity to debt. Keywords: Propensity to indebtedness; Multinomial logit; Compulsive shopping; Materialism; Socioeconomic and demographic variables.
\end{abstract}

Potrich, A. C. G., Vieira, K. M., Coronel, D. A. \& Bender, R. (2016). Modelando a propensão ao endividamento: os fatores comportamentais e socioeconômicos são determinantes? En: Revista de la Facultad de Ciencias Económica: Investigación y Reflexión. rev.fac.cienc.econ, XXIV (2), DOI: http://dx.doi.org/10.18359/rfce.2214

JEL: D10, D 14, G02.

\section{Introdução}

A estabilidade econômica brasileira, as facilidades de acesso ao crédito, a ampla oferta de produtos financeiros, e os incentivos fiscais oferecidos pelo governo têm estimulado o consumo e movimentado a economia (Braido, 2014). Por outro lado, essa conjuntura econômica tem feito com que os indivíduos consumam além de suas condições financeiras e assim gere uma ascendência no nível de dívida da sociedade.
Neste sentido, a manutenção de níveis crescentes e elevados de dívida é consequência de um cenário macroeconômico mais favorável ao consumo, o qual combina política fiscal expansionista com afrouxamento monetário, e mais desfavorável à manutenção da capacidade de pagamento do consumidor. No entanto, tais fatores provocam algumas consequências, dentre as quais se destaca o crescimento acelerado nos níveis de endividamento. 
Entende-se por endividamento o processo de assumir ou contrair dívidas (Ferreira, 2006). Assim, decisões financeiras incorretas podem levar ao endividamento, o qual quando se torna excessivo é chamado de sobre-endividamento, quando há impossibilidade de pagamento (Zerrenner, 2007). De acordo com a Pesquisa de Endividamento e Inadimplência do Consumidor (Peic), da Confederação Nacional do Comércio de Bens, Serviços e Turismo (CNC), realizada em outubro de 2014, o percentual de famílias que relataram ter dívidas entre cheque pré-datado, cartão de crédito, cheque especial, carnê de loja, empréstimo pessoal, prestação de carro e seguro alcançou 63,1\% em setembro de 2014, mostrando um aumento em relação aos $61,4 \%$ de setembro de 2013 (CNC, 2014).

Nota-se que o nível de endividamento das famílias brasileiras vem incrementando-se ano a ano. Todavia quando se busca fatores que expliquem o aumento do endividamento não se identifica uma consonância entre as pesquisas. Alguns estudos ressaltam a representatividade do materialismo (Ponchio \& Aranha, 2008; Ponchio, 2006), outros o comportamento de compra compulsiva (Koram et al., 2006; Veludo-De-Oliveira, Ikeda \& Santos, 2004; O'Guinn \& Faber, 1989) e ainda há aqueles que salientam a influência de variáveis socioeconômicas e demográficas na propensão ao endividamento (Faber \& O'Guinn, 1992; Ponchio, 2006; Muller, 2010; Gathergood, 2012; Bricker et al., 2012; Lucena \& Marinho, 2013).

Cada um destes fatores contribui de maneira distinta para o endividamento pessoal. O materialismo, por exemplo, eleva a propensão ao endividamento pelo fato de ser a importância atribuída por cada pessoa na aquisição de um bem ou serviço (Richins \& Dawson, 1992). Na medida em que essa importância aumenta os valores materialistas tornam-se mais dominantes, estimulando os gastos e consequentemente contribuindo para o crescimento das dívidas (Garðarsdóttir \& Dittmar, 2012). Da mesma maneira que o materialismo, as compras compulsivas, ou seja, aquela compra repentina, não planejada e associada a um forte desejo e sentimento de prazer também faz com que o consumo aumente indiscriminadamente, sem que a pessoa analise suas condições financeiras para arcar com as obrigações auferidas (Lejoyeux \& Weinstein, 2010).

Além de fatores comportamentais, identifica-se também influência das variáveis socioeconômicas e demográficas na propensão ao endividamento, tais como a idade, em que a maioria dos estudos indica jovens como sendo mais propensos ao endividamento (Zuckerman \& Kuhlman, 2000; Ponchio, 2006); o estado civil, sendo os indivíduos solteiros os que apresentam maior propensão ao endividamento (Gathergood, 2012; Flores, 2012); a escolaridade, onde estudos apontam a existência de uma relação negativa entre o nível de escolaridade e a propensão ao endividamento (Ponchio, 2006); a renda, sendo que quanto menor o nível de renda mais vulneráveis a dívida (Zerrenner, 2007; Bricker et al., 2012); entre outras variáveis.

Portanto, o entendimento da propensão ao endividamento, vai além de fatores econômicos, uma vez que envolve fatores comportamentais e sóciodemográficos. Num cenário em que as famílias são estimuladas a consumir e os níveis de crédito são crescentes, a compreensão do papel destes fatores na propensão ao endividamento torna-se ainda mais relevante, na medida em que pode auxiliar na adoção de estratégias e ações que evitem o sobreendividamento e, consequentemente, a inadimplência. Assim, este estudo, visa analisar a influência de fatores comportamentais e das variáveis socioeconômicas e demográficas na propensão ao endividamento dos indivíduos.

A importância do estudo também está em seu caráter inovador, dado que, em âmbito brasileiro, há poucos registros de pesquisas que buscam compreender os determinantes comportamentais da propensão ao endividamento. Para tal, conforme afirmam Livingstone \& Lunt (1992), é necessária uma análise multidisciplinar, pois esta proporciona uma visão mais ampla e correta dos fatores que levam o sujeito a endividar-se. Assim, este trabalho contribui para a ampliação do acervo de pesquisas empíricas acerca da propensão ao endividamento ao encontrar os determinantes comportamentais que podem afetar positiva e negativamente a propensão que o indivíduo possui para endividar-se, gerando um 
conhecimento mais aprofundado sobre o assunto que ainda é incipiente em âmbito brasileiro. Através dos resultados auferidos poderão ser desenvolvidas ações que tenham por finalidade auxiliar órgãos governamentais e empresariais a detectar aqueles propensos ao endividamento, uma vez que o seu perfil será analisado de forma mais completa e compreensível.

O trabalho está estruturado em cinco seções, incluindo a introdução. A segunda apresenta as bases teóricas e empíricas que sustentam este trabalho; na terceira, são apresentados os procedimentos metodológicos adotados; na quarta encontram-se as análises e discussões dos resultados; e por último, são tecidas as considerações mais relevantes acerca do estudo realizado, limitações e sugestões para pesquisas futuras.

\section{Propensão ao endividamento}

Ao longo dos anos, o consumidor vem consolidando o seu comportamento de compra e o estímulo ao consumo estão cada vez mais presentes no cotidiano. No entanto, este aumento de crédito e incentivo ao consumo tem resultado em alto nível de endividamento, o qual corresponde a um problema de ordem social, da chamada "sociedade do consumo" (Slomp, 2008).

De acordo com Ferreira (2006), o endividamento tem origem no verbo endividar-se, o qual indica assumir ou contrair dívidas e, dependendo do nível de endividamento, os indivíduos podem comprometer uma parcela significativa de sua renda. Com isso, quando o indivíduo sente-se impossibilitado de quitar os seus compromissos financeiros, tem-se uma situação distinta, chamada de sobre-endividamento. Esse termo caracteriza a situação em que o indivíduo é incapaz de pagar as suas dívidas com a renda que recebe, o qual pode acontecer de forma ativa, quando o indivíduo contribui para a dívida ou de forma passiva, quando não contribui, como, por exemplo, em casos de doença e desemprego (Brusky \& Magalhães, 2006; Keese, 2010). Reifner et al. (2010) defendem que os consumidores sobreendividados devem ser "reciclados" pelo sistema financeiro, permitindo que participem mais uma vez do mercado e da sociedade e não sejam excluídos.
Evidencia-se ainda, que muitos são os estudos que demonstram altos níveis de endividamento tanto em países subdesenvolvidos como desenvolvidos. Dessa forma, Dominguez \& Robin (2007) verificam altos níveis de endividamento na realidade financeira norte-americana. No mercado brasileiro, a Confederação Nacional do Comércio de Bens, Serviços e Turismo (CNC), realiza desde 2010 uma pesquisa mensal que avalia o endividamento e inadimplência do consumidor. Segundo os dados divulgados, o percentual das famílias endividadas alcançou $63,1 \%$ em setembro de 2014, diminuindo em relação aos $63,6 \%$ observados em agosto de 2014, mas aumentando em relação aos $61,4 \%$ de setembro de 2013. Já o percentual de famílias com dívidas ou contas em atraso representou, em setembro de 2014, 19,2\% do total de famílias endividadas, enquanto que o percentual de famílias que declarou não ter condições de pagar suas contas ou dívidas em atraso e que, portanto, permaneceriam inadimplentes alcançou $5,9 \%$ (CNC, 2014).

Diante do elevado nível de endividamento, o meio acadêmico tem buscado identificar os efeitos que essas circunstâncias geram na saúde mental das pessoas. Nesse âmbito, o Observatório de Endividamento dos Consumidores da Faculdade de Economia da Universidade de Coimbra (2002) apontou possíveis aspectos sociais e psicológicos desenvolvidos após o não comprimento dos prazos de pagamento das dívidas (sobre-endividamento), como a marginalização e exclusão social, o alcoolismo, a dissolução das famílias, as perturbações da saúde física e mental. Jacoby (2002) corrobora, afirmando que os indivíduos podem limitar sua capacidade de buscar assistência médica, devido aos custos incorridos. Com isso, sua saúde física e mental também poderá ser prejudicada.

Neste mesmo panorama, Keese \& Schmitz (2011) destacam o desenvolvimento de problemas de saúde, como o stress e a angústia, menor percepção da capacidade de gerenciamento do dinheiro, menor sensação de bem-estar financeiro e emoções negativas. Plagnol (2011) ratifica essas evidências, exibindo que o endividamento ocasiona problemas emocionais. Partindo dessas evidências, segundo Lucke et al. (2014), percebe-se que a dívida altera a qualidade de vida dos indivíduos que passam a ter um agravo 
na saúde psicológica, podendo chegar a patamares drásticos como o desencadeamento de sintomas de depressão, doenças do coração e insônia. De mesma forma, Loiola (2014) revela que quanto maior o volume de dívidas (em meses de salário), maior o estresse financeiro. Há outro agravo nestas situações, quando a pessoa, dado o nível de inadimplência, fica com seu nome vinculado a um cadastro de dívida ativa $e$ em alguns casos pode até se considerar excluso do sistema de crédito, tornando inacessível o consumo a prazo (Lucke et al., 2014).

Ferreira (2006) ainda acrescenta que as pessoas endividadas têm pouca ou nenhuma habilidade em lidar com dinheiro, não elaboram um planejamento financeiro e não conseguem passar o mês dentro do orçamento fazendo com que os mesmos passem a trabalhar exclusivamente para quitar as dívidas, dificultando a recuperação do equilíbrio econômico. Alguns conseguem reverter a situação, enquanto outros necessitam de ajuda, como orientações prévias a respeito de decisões financeiras ou até mesmo auxílio financeiro para liquidar as dívidas. Nos Estados Unidos, alguns estados oferecem um padrão de vida mínimo para a população, contribuindo com famílias que estão sobre-endividadas, caso de pessoas que são incapazes de pagar o aluguel, o estado oferece alojamentos alternativos. Desta forma, a própria sociedade do consumo torna-se responsável e ao mesmo tempo é influenciada pelo endividamento do consumidor (Reifner et al., 2010).

Todas essas situações representam adversidades financeiras que estão cada vez mais eminentes, seja pela ampla disseminação de produtos financeiros e pela oferta de crédito (Braido, 2014), pelas campanhas apelativas de marketing (Lucke et al., 2014), pelo surgimento de eventualidades que exigem desembolsos imediatos (Santos \& Silva, 2014) ou até mesmo pelos aspectos comportamentais, como as compras compulsivas (Kyrius, Mcqueen \& Moulding, 2013) e o materialismo (Richins, 2011).

\subsection{Propensão ao endividamento e seus determi nantes comportamentais}

Compreender os fatores comportamentais que orientam as decisões dos indivíduos não é uma tarefa fácil, pois estes envolvem muita subjetividade e incerteza, entretanto são peças fundamentais para justificar as mesmas. Para Moura (2005), o problema do endividamento exige uma visão multidisciplinar, utilizando as variáveis simultaneamente e identificando a magnitude de cada uma. Assim, diversos estudos apontam a influência de dois fatores comportamentais principais que estariam associados à propensão ao endividamento: o materialismo $e$ as compras compulsivas.

A primeira hipótese é constituída a partir da concepção de que indivíduos mais materialistas estão mais propensos a contratar créditos para consumo, obtendo atitudes mais positivas frente ao endividamento, ou seja, quanto maior o nível de materialismo, mais propenso ao endividamento a pessoa será (Ponchio, 2006). Nesse sentido, ao investigar a relação entre materialismo e dívida de 322 indivíduos norte-americanos, Watson (2003) encontrou como resultado que quanto mais materialista for o indivíduo maior a tendência de ele se auto classificar como gastador, utilizar o crediário, manter atitudes positivas frente à dívida e realizar empréstimos para comprar produtos de luxo. Tendo por base a Escala dos Valores Materialistas desenvolvida por Richins \& Dawson (1992) e a técnica de Modelagem de Equações Estruturais, os autores constataram que o materialismo atua como determinante da propensão ao endividamento e que indivíduos mais materialistas tendem a ter uma atitude mais positiva em relação à dívida que indivíduos não materialistas. No contexto brasileiro, destacam-se os estudos de Ponchio (2006) e Trindade (2009). Ambos concluíram que pessoas materialistas apresentam atitudes mais favoráveis ao uso do crédito e maior propensão ao endividamento.

Nesse mesmo sentido, o materialismo também amplia o nível de consumo dos indivíduos, pois faz com que as pessoas atribuam uma importância muito elevada à posse de bens materiais, julgando a si e aos outros pelos bens materiais obtidos (Richins, 2011). Assim, quanto mais as pessoas considerarem relevante os bens materiais, maior será a aspiração para compra e consequentemente mais propensos a endividarem-se (Santos \& Fernandes, 2011). Garðarsdóttir \& Dittmar (2012) destacam perspectivas semelhantes, revelando que a 
sociedade mostra-se ainda mais consumista e que os valores e objetivos materialistas têm se tornado mais dominantes, estimulando os gastos e, consequentemente, contribuindo para o crescimento das dívidas.

Indivíduos altamente materialistas, conforme Richins \& Dawson (1992), tomam como referência indivíduos de nível socioeconômico superior fazendo com que os mesmos, a fim de acompanhar as demandas de consumo, sejam mais propensos a exibir comportamentos favoráveis à contração de dívidas. Com base nisso, o presente estudo espera encontrar esta relação demonstrada pelos autores, na qual o materialismo impacta na propensão ao endividamento, através de uma relação positiva, ou seja, quanto maior o nível de materialismo, maior a propensão ao endividamento.

A segunda hipótese trata da influência do fatorcomportamental compra compulsiva na propensão ao endividamento, em que a principal consequência gerada pelo comportamento de compra compulsiva de um indivíduo é a maior propensão ao endividamento (Roberts \& Jones, 2001). Esse panorama é evidenciado, pois a aquisição compulsiva de produtos, na maioria das vezes desnecessária pelas pessoas, ocasiona em restrição orçamentária, fazendo com que em períodos futuros os compromissos fixados não possam ser cumpridos, maximizando o problema do endividamento, poispossivelmente a pessoa continuará consumindocompulsivamente sem condições financeiras para isso (Carvalho \& Alves, 2010). O'Guinn \& Faber (1989) ratificam essa concepção ao identificar que compradores compulsivos apresentam baixa auto-estima, alto grau de compulsividade e elevada tendência de imaginação e fantasia, aspectos que contribuem para o consumo elevado, o qual gera como consequência alto grau de endividamento, depressão e discórdia doméstica.

Além destes, outros autores como Figueira \& Pereira (2014) realizaram uma análise dos antecedentes do endividamento do consumidor e verificaram que a compra compulsiva influencia positivamente na propensão ao endividamento. Kyrius, McQueen \& Moulding (2013) corroboram com essa linha de pensamento, elucidando que a compra compulsiva opera como um ciclo negativo, pois o consumo, no curto prazo, tende a aliviar emoções negativas, no entanto, no longo prazo, a falta de satisfação com os objetos adquiridos $e$ as consequências negativas decorrentes da compra compulsiva, tais como o endividamento, servem para perpetuar a depressão $e$ a baixa auto-estima. Com isso, a compra compulsiva pode ser entendida como uma atividade que produz recompensas de curto prazo e consequências negativas, como o endividamento, no longo prazo.

Dentro desse escopo e tomando por base as pesquisas mencionadas espera-se encontrar uma relação positiva entre compras compulsivas e dívida. Dito de outra forma espera-se que compradores compulsivos consumam sem levar em conta suas condições financeiras, e consequentemente, endividam-se.

\subsection{Propensão ao endividamento e seus determi- nantes socioeconômicos e demográficos}

A importância do crédito para os consumidores e para economia está cada vez mais visível. Uma vez que as dificuldades econômicas levam as famílias a utilizar uma hierarquia de decisões em relação ao consumo, onde os indivíduos tendem a se adaptar as crises e recessões, optando por uma compra mais barata, uma compra menor, uma compra mais duradoura e outras escolhas mais conscientes (Garling et al., 2009). Os autores destacam que esta adaptação pode implicar em mudanças no estilo de vida das famílias, sendo os jovens mais flexíveis do que as pessoas mais velhas. Mas, por outro lado, a experiência das pessoas mais velhas pode contribuir nos momentos de recessão e fazer com que os mesmos enfrentem de maneira mais otimista a situação do que os jovens.

Diante deste contexto, outra dimensão bastante relevante para a compreensão da propensão ao endividamento dos indivíduos são os aspectos socioeconômicos e demográficos. Frade et al. (2008) afirmam que o perfil de endividamento está estritamente relacionado com a fase do ciclo de vida que encontram-se os indivíduos, sendo importante relacionar aspectos como gênero, idade, estado civil, renda, entre outros. 
Quanto à variável gênero, ainda não foi encontrado um consenso quanto à relação com a propensão ao endividamento. Autores como Wang, Lu \& Malhotra (2011) constataram que as mulheres endividamse com menor frequência do que os homens, devido, principalmente, a prudência na hora de tomar as decisões financeiras ou, ainda, por serem mais avessas ao risco (Keese, 2010). Por outro lado, Vieira et al. (2014) encontraram que as mulheres são mais propensas ao endividamento e Faber \& O'Guinn (1992) afirmam que as mulheres acabam se endividando mais devido a maior predisposição a incorrer em comportamentos de compra compulsiva. Além disso, alguns autores ainda argumentam não terem encontrado diferença significativa quanto ao endividamento entre homens e mulheres, como Norvilitis, Szablicky \& Wilson (2003), Norvilitis et al. (2006) e Hancock, Jorgensen \& Swanson (2013).

Levando em consideração a propensão ao endividamento e a idade, percebe-se que a maioria dos estudos indica que as pessoas mais jovens como sendo aquelas mais propensas ao endividamento. De acordo com Norvilitis et al. (2006), isso acontece por causa da expectativa positiva de renda futura, ou seja, os jovens que acreditam que no futuro possuirão níveis altos de renda são mais favoráveis ao crédito e, ainda, tolerantes ao endividamento. Além disso, Worthy, Jonkman \& Blinn-Pike (2010) corroboram esses resultados, afirmando que pessoas entre 18 e 25 anos são mais propensos ao endividamento tendo em vista que estão dispostos a assumir riscos e apresentam menor estabilidade financeira quando comparados ao demais. Zuckerman \& Kuhlman (2000) relacionam este resultado com a formação do exército, que seleciona homens mais jovens para exercerem o papel de soldados, não sendo esta escolha somente pela força física, mas por sua disposição para arriscar suas vidas em combate. Além disso, estudos revelam as pessoas mais jovens como mais vulneráveis a comportamentos inadequados no uso do dinheiro e consequentemente ao endividamento (Gathergood, 2012; Sevim, Temizel \& Sayilir, 2012). Especificamente, Vieira, Flores \& Campara (2014), detectaram que pessoas de até 22 anos possuem maior tendência ao endividamento que as demais faixas etárias, prin- cipalmente quando se analisa a diferença de média em relação aos indivíduos com mais de 45 anos.

No que tange aos indivíduos possuir dependentes, Keese (2010) afirma que as famílias com maior número de crianças obtêm maiores níveis de dívidas do que aquelas que possuem mais adultos. Resultados semelhantes foram encontrados por Flores (2012), que justifica dizendo que as pessoas que ainda não constituíram uma família ou que já constituíram, mas no momento vivem sozinhas, tendem a menor propensão ao endividamento, tendo em vista que não possuem compromisso exclusivo com a família.

Ao verificar a relação entre escolaridade e propensão ao endividamento, Ponchio (2006) obteve uma relação negativa entre o nível de escolaridade e a propensão ao endividamento, indicando que aqueles com maiores níveis de escolaridade tendem a assumir menores dívidas, resultado similar encontrado por Gathergood (2012) e Flores (2012). Corroborando, Vieira, Flores \& Campara (2014) também detectaram que quanto menor o grau de escolaridade do indivíduo maior é sua tendência a assumir dívidas. Já levando em consideração à ocupação, para Gathergood (2012) e Flores (2012), existe uma relação negativa entre as variáveis. Vieira, Flores \& Campara (2014) verificaram que os indivíduos que não trabalham apresentam uma maior propensão ao endividamento se comparados com as demais ocupações.

Por fim, verificando a relação existente entre o nível de renda e a propensão ao endividamento, observa-se que quanto menor o nível de renda mais vulneráveis à dívida as pessoas ficam (Bricker et al., 2012; Lucena et al., 2014; Vieira, Flores \& Campara, 2014). Especificamente, Zerrenner (2007) avaliou o endividamento dos consumidores de baixa renda de São Paulo, considerando indivíduos com rendas de até três salários mínimos. De acordo com os resultados, encontrou-se uma relação contrária entre os fatores, sendo que quanto menor é a renda do indivíduo, maior será a sua propensão ao endividamento. Segundo Santos \& Souza (2014), os resultados encontrados por eles também sustentam a hipótese que as pessoas de rendas mais baixas são mais propensas ao endividamento em comparação às demais classes econômicas, justificadas pelo fato 
da exigência de diversas facilidades que são proporcionadas pelas agências e pelas instituições financeiras, uma vez que os produtos de crédito facilitam a utilização do dinheiro e, acabam por consequência, podendo ser enquadrados no débito financeiro.

Complementando, o Tabela 1 apresenta uma síntese das pressuposições acerca da relação existente entre as variáveis socioeconômicas e demográficas $e$ a propensão ao endividamento.

\section{Método}

Esta seção tem como escopo apresentar a modelagem teórica $e$ as variáveis utilizadas a fim de atingir aos objetivos estabelecidos. Dessa forma, essa seção descreve a população e amostra, o instrumento de coleta de dados, além do modelo estimado e das técnicas de análise dos dados.

\subsection{População e amostra}

A população alvo do estudo compreende os residentes da Mesorregião Centro Ocidental Rio-Grandense, a qual é formada pela união de 31 municípios, agrupados em 3 microrregiões (Microrregião de Santa Maria, de Restinga Seca e de Santiago), que juntas totalizam uma população de 536.938 habitantes (IBGE, 2010).

Para o processo de amostragem, considerou-se um erro amostral de 2\%, com 95\% de confiança e uma população finita de 536.938 que representa o total dos que residem na região escolhida pelo estudo. Sendo assim, a amostra totalizou 2.391 indivíduos distribuídos proporcionalmente entre as cidades da Mesorregião Centro Ocidental Rio-Grandense. A aplicação do instrumento de coleta de dados foi realizada proporcionalmente em cada estrato, no caso, em cada município, de forma aleatória, em ambiente externo, através do contato com os moradores dispostos a participar da pesquisa.

Tabela 1. Síntese das pressuposições acerca da relação existente entre variáveis socioeconômicas e demográficas e a propensão ao endividamento

\begin{tabular}{|c|c|c|}
\hline Variáveis & Pressuposição & Autores \\
\hline \multirow{3}{*}{ Gênero } & As mulheres são mais propensas ao endividamento. & $\begin{array}{l}\text { Faber \& O'Guinn (1992); Carvalho \& Alves (2010); Trindade, Righi \& } \\
\text { Vieira (2012); Vieira et al. (2014). }\end{array}$ \\
\hline & Os homens são mais propensos ao endividamento. & $\begin{array}{l}\text { Muller (2010); Keese (2010); Wang, Lu \& Malhotra (2011); Lucena \& } \\
\text { Marinho (2013). }\end{array}$ \\
\hline & $\begin{array}{l}\text { Não há diferenças significativas entre mulheres e ho- } \\
\text { mens. }\end{array}$ & $\begin{array}{l}\text { Norvilitis, Szablicky \& Wilson (2003); Norvilitis et al. (2006); Hancock, } \\
\text { Jorgensen \& Swanson (2013). }\end{array}$ \\
\hline Idade & Os jovens são mais propensos a endividarem-se. & $\begin{array}{l}\text { Norvilitis et al. (2006); Zuckerman \& Kuhlman (2000); Ponchio (2006); } \\
\text { Worthy, Jonkman \& Blinn-Pike (2010); Gathergood (2012); Sevim, Tem- } \\
\text { izel \& Sayilir (2012); Vieira, Flores \& Campara (2014). }\end{array}$ \\
\hline $\begin{array}{l}\text { Possuir } \\
\text { dependentes }\end{array}$ & $\begin{array}{l}\text { Quanto maior o número de filhos maior a propensão } \\
\text { ao endividamento. }\end{array}$ & Keese (2010); Flores (2012). \\
\hline Escolaridade & $\begin{array}{l}\text { As pessoas com menores níveis de escolaridade ten- } \\
\text { dem a assumir maiores dívidas. }\end{array}$ & $\begin{array}{l}\text { Ponchio (2006); Gathergood (2012); Flores (2012); Vieira, Flores \& } \\
\text { Campara (2014). }\end{array}$ \\
\hline Ocupação & $\begin{array}{l}\text { Os indivíduos com menores taxas de emprego apre- } \\
\text { sentam maior nível de endividamento. }\end{array}$ & $\begin{array}{l}\text { Gathergood (2012); Flores (2012); Keese (2010); Vieira, Flores \& Cam- } \\
\text { para (2014). }\end{array}$ \\
\hline Renda & $\begin{array}{l}\text { Quanto menor o nível de renda mais vulneráveis a } \\
\text { dívida às pessoas ficam. }\end{array}$ & $\begin{array}{l}\text { Zerrenner (2007); Bricker et al. (2012); Lucena et al. (2014); Vieira, Flo- } \\
\text { res \& Campara (2014); Santos \& Souza (2014). }\end{array}$ \\
\hline
\end{tabular}

Fonte: Elaborado pelos autores. 


\subsection{Instrumento de coleta de dados}

O instrumento de pesquisa foi elaborado com base na literatura (Richins, 2004; Leite et al., 2011; Flores, 2012), utilizando questões de múltipla escolha, as quais avaliaram o perfil dos respondentes e determinam a propensão ao endividamento, além de questões do tipo likert de cinco pontos para avaliar os fatores investigados: materialismo e compras compulsivas.

Assim, a primeira questão é composta por três alternativas que tratam da propensão ao endividamento, a qual foi desenvolvida originalmente por Flores (2012) e busca identificar se os indivíduos gastam menos, igual ou mais do que ganham. Nesse sentido, aqueles que afirmam gastar igual ou mais do que ganham, mais propensos ao endividamento são, respectivamente.

No segundo bloco do instrumento busca-se identificar o nível de materialismo dos entrevistados. A escala utilizada foi desenvolvida inicialmente por Richins \& Dawson (1992), a qual possuía dezoito itens. Todavia Richins (2004) buscou reduzir o número de variáveis para mensurar o materialismo, testando escalas com quinze, nove, seis e três itens, e concluiu que a escala com nove variáveis seria a mais adequada para mensuração. Partindo desse pressuposto, utilizam-se os nove itens indicados por Richins (2004), sendo que nessa escala, com exceção da primeira questão, quanto maior o grau de concordância, mais materialista é o respondente.

Nessa mesma perspectiva, busca-se com o terceiro bloco de questões compreender o consumo compulsivo dos entrevistados. Para isso, utiliza-se a escala original de Faber \& O'Guinn (1992) adaptada e reaplicada no Brasil por Leite et al. (2011), os quais realizaram os procedimentos psicométricos para a revalidação da escala no cenário brasileiro, a partir de cinco passos: i) tradução inicial; ii) síntese das traduções; iii) tradução reversa; iv) revisão por especialistas e v) aplicação piloto ou testagem preliminar. Os autores validaram sete questões, as quais já tinham sido selecionadas por Faber \& O'Guinn (1992) como as mais significativas para o modelo. O intuito maior da aplicação dessa escala é a possibilidade de visualizar quão voltados ao consumo os respondentes estão, ou seja, como eles se comportam diante da diversidade de produtos e serviços ofertados, se compram apenas quando necessitam ou adquirem pelo simples prazer de consumir. Sendo assim, quanto mais os entrevistados concordam com as informações, mais comportamento de compra compulsiva eles apresentam.

Na última seção estão listadas as nove questões referentes ao perfil dos respondentes, o qual é representado pelas variáveis: gênero, idade, se possui dependentes, nível de escolaridade, ocupação e renda média mensal familiar.

\subsection{Técnicas de análise dos dados e modelo esti mado}

Para a análise dos dados foram utilizadas estatísticas descritivas e técnicas de análise multivariada, com o auxílio dos softwares SPSS 20.0®, $\mathrm{Amos}^{\mathrm{TM}}$ e Stata $12 ®$. Inicialmente, foi calculada a estatística descritiva das variáveis de perfil, visando traçar um panorama geral dos respondentes.

Posteriormente, com o objetivo de validação dos fatores foi utilizada a análise fatorial confirmatória (AFC), que segundo Byrne (2010) é apropriada quando há algum conhecimento subjacente, seja teórico e/ou empírico, da estrutura das variáveis latentes. Neste contexto, Byrne (2010) considera necessária a análise de diversos índices de ajustamento, de forma a avaliar a adequabilidade do modelo proposto aos dados da amostra. A validade do modelo de mensuração foi avaliada por meio da verificação da validade convergente, a confiabilidade e a unidimensionalidade de cada fator, seguindo recomendação de Garver \& Mentzer (1999) e Hair et al. (2010).

A validade convergente de cada fator foi analisada pela observação da magnitude e da significância estatística dos coeficientes padronizados e pelos índices de ajustes absolutos: estatística qui-quadrado $\left(\chi^{2}\right)$, Root Mean Square Residual (RMR), Root Mean Square Error of Approximation (RMSEA), Goodness of Fit Index (GFI) $e$ índices de ajuste comparativos: Comparative Fit Index (CFI), Normed Fit Index (NFI), Tucker-Lewis Index (TLI). Não há 
um consenso na literatura sobre valores aceitáveis para estes índices. No entanto, segundo uma pesquisa realizada por Hooper, Coughlan \& Mullen (2008), um bom modelo ajustado proporciona um qui-quadrado não significativo ao nível de $5 \%$ ou então a razão qui-quadrado/graus de liberdade variam de menores que cinco até menores que dois. Para CFI, GFI, NFI e TLI, sugerem-se valores maiores que 0,95 e o RMR e o RMSEA, devem ficar abaixo de 0,05 e 0,08, respectivamente. Para este estudo, foram utilizadas as recomendações de Hooper, Coughlan \& Mullen (2008) nos índices CFI, GFI, NFI e TLI (valores maiores que 0,95), RMR (valores menores que 0,05) e RMSA (valores menores que $0,08)$. Já para a razão qui-quadrado/graus de liberdade, valores menores que cinco foram aceitáveis.

Para mensurar a confiabilidade dos fatores utilizouse o Alpha de Cronbach, em que valores superiores a 0,6 têm sido considerados aceitáveis para pesquisas de natureza exploratória (Hair et al., 2010). A verificação da unidimensionalidade do fator foi realizada mediante a avaliação dos resíduos padronizados, sendo que valores absolutos menores que 2,58 não sugerem problema (Hair et al., 2010). Além disso, todos os modelos foram estimados utilizando bootstrap máxima verossimilhança, com tamanho amostral de 1000, conforme sugerido por Cheung \& Lau (2008).

Ressalta-se que para se alcançar índices satisfatórios, optou-se pela estratégia de aprimoramento, na qual, a partir de um modelo inicialmente proposto são feitas modificações para se chegar a um modelo ajustado. Dessa forma, foram retiradas as variáveis com cargas fatoriais padronizadas não significativas $e$ as que apresentaram valores abaixo de 0,3 e não contribuíam significativamente para o modelo (Hair et al., 2010), além da inserção de correlações entre os erros das variáveis observadas, sugeridas pelo relatório do AMOS e que faziam sentido teórico. Kline (2011) afirma que correlações entre os resíduos podem ser inseridas quando são justificáveis.

Após realizar a análise fatorial confirmatória dos fatores, buscou-se identificar a probabilidade dos indivíduos serem mais ou menos propensos a endividarem-se, condicional a um conjunto de fatores e variáveis socioeconômicas e demográficas, por meio de um modelo Logit Multinomial. Optou-se por este método, pois ele possibilita a utilização de uma variável dependente com mais de duas categorias as quais não devem ser ordenadas de forma significativa (Gujarati \& Porter, 2011). Conforme Greene (2008) e Cameron \& Trivedi (2009), o modelo Logit Multinomial pode ser apresentado pela Equação 1.

$$
p_{i j}=\operatorname{Pr}\left(Y_{i}=j \mid x_{i}\right)=\frac{e^{x^{\prime} \beta_{j}}}{\sum_{j=1}^{m} e^{x_{i}{ }^{\prime} \beta_{j}}} j=1,2, \ldots, m .
$$

Em que, $Y_{i}$ é a variável aleatória que indica a escolha; $P_{i j}=\operatorname{Pr}\left(Y_{i}=j \mid \chi_{i}\right)$ é a probabilidade de um indivíduo $i$ optar pela escolha $j ; \chi_{i}$ é a matriz de atributos observáveis para os indivíduos, e; $\beta$ é o vetor de parâmetros a serem estimados.

Os respondentes podem apresentar uma baixa propensão a endividarem-se $(\mathrm{j}=0)$; uma propensão mediana a endividarem-se $(j=1)$ e uma alta propensão a endividarem-se $(j=2)$. Os fatores que afetam esta propensão podem ser o comportamento materialista, comportamento de compras compulsivas, gênero, idade, possuir dependentes, escolaridade, ocupação e renda familiar.

O modelo Logit Multinomial é estimado pelo método de máxima verossimilhança. Todavia, os coeficientes estimados não representam diretamente as respostas marginais das variáveis explicativas e são de difícil interpretação, contudo é possível obter a partir deles os logs para $j-1$ razões das probabilidades (Greene, 2008). Assim, é necessário calcular os efeitos marginais para analisar de forma mais adequada os resultados, os quais são obtidos a partir da diferenciação do modelo especificado. A Equação 2 apresenta a operacionalização desse processo.

$$
\delta_{i j}=\frac{\partial p_{i j}}{\partial x_{i}}=p_{i j}\left[\beta_{j}-\sum_{j=1}^{m} p_{i j} \beta_{k}\right]=p_{i j}\left[\beta_{j}-\overline{\beta_{i}}\right]
$$

Uma alteração em $\mathrm{x}$ provoca uma alteração na probabilidade de y ocorrer em que $\overline{\beta_{i}}=\sum^{m} p_{i j} \beta_{j}$ é a probabilidade média de $\beta_{j}$. Desta forma, tem-se j-1 equações das quais se consegue obter alguma in- 
terpretação acerca dos coeficientes estimados, que nesse caso possibilitaria uma forma de expressar o efeito sobre a probabilidade de escolha da alternativa $j$ em relação à alternativa $J$ decorrente de uma mudança marginal no valor de cada variável específica.

Para tanto, o efeito marginal varia com o ponto de estimação, $\chi_{i}$, uma vez que $P_{i j}$ varia com $\chi_{i}$. Para cada $\chi_{i}$ particular, o efeito marginal, $\frac{\partial p_{i j}}{\partial x_{k}}$, não necessariamente terá o mesmo sinal de $\beta_{j k}$, sendo que, o efeito marginal será positivo se $\beta_{j} \beta_{i}$. Os erros-padrão podem ser estimados usando o método delta.

Posterior à definição do modelo, busca-se pressupostos que possam trazer robustez aos resultados. Assim, para testar a adequabilidade do modelo foram realizados os testes de diagnóstico: testes de Wald e de LR para testar se os coeficientes de cada previsor são significativamente diferentes de zero. Se isso ocorrer, pode-se assumir que o previsor está contribuindo de forma significativa para a previsão da variável de saída (Field, 2009); testes de Wald e LR para comparação de variáveis, utilizados para testar se as combinações entre as variáveis são diferentes de zero; os testes Hausman e Small-Hsiao para avaliar a Independência das Alternativas Irrelevantes (IIA), e; para testar adequabilidade do modelo, fez-se uso do teste de Hosmer-Lemeshow, que relaciona os dados as suas probabilidades estimadas da mais baixa a mais alta, fazendo um teste quiquadrado para determinar se as frequências observadas estão próximas das frequências esperadas; tendo como hipótese nula o ajustamento adequado do modelo (Archer, Lemeshow \& Hosmer, 2007).

Para ilustrar de maneira mais pontual as características das variáveis apresenta-se o Tabela 2.

Tabela 2. Variáveis utilizadas na estimação do modelo

\begin{tabular}{|c|c|c|}
\hline Fator & Alternativas & \\
\hline $\begin{array}{l}\text { Propensão ao } \\
\text { endividamento }\end{array}$ & $\begin{array}{l}1 \text { - Gasto menos do que ganho. (Propensão BAIXA ao endividamento) } \\
2 \text { - Gasto igual ao que ganho. (Propensão MEDIANA ao endividamento) } \\
3 \text { - Gasto mais do que ganho. (Propensão ALTA ao endividamento) }\end{array}$ & \\
\hline Dimensões & Pergunta que deu origem aos dados & Formato \\
\hline Materialismo & $\begin{array}{l}\text { Q2. Eu tento manter uma vida simples, se consideradas as minhas posses. } \\
\text { Q3. As coisas que possuo dizem muito sobre como está a minha vida atualmente. } \\
\text { Q4. Eu gosto de possuir coisas que impressionem as pessoas. } \\
\text { Q5. Eu admiro pessoas que possuem casas, carros e roupas caras. } \\
\text { Q6. Comprar me dá muito prazer. } \\
\text { Q7. Eu gosto de muito luxo em minha vida. } \\
\text { Q8. Minha vida seria melhor se eu tivesse algumas coisas que não tenho. } \\
\text { Q9. Eu seria mais feliz se eu pudesse comprar mais coisas. } \\
\text { Q10. Às vezes me chateio um pouco por não poder comprar todas as coisas que eu gostaria. }\end{array}$ & $\begin{array}{l}\text { Escala do } \\
\text { tipo Likert } \\
0 \text { a } 5 \text { pontos } \\
1 \text { (Discordo totalmente) } \\
2 \text { (Discordo) }\end{array}$ \\
\hline Compras Compulsivas & $\begin{array}{l}\text { Q11. Se sobra algum dinheiro ao final do período de pagamento, tenho que gastá-lo. } \\
\text { Q12. Sinto que os outros ficariam horrorizados se soubessem dos meus hábitos de comprar. } \\
\text { Q13. Comprei coisas apesar de não conseguir pagar por elas. } \\
\text { Q14. Emiti um cheque quando sabia que não tinha dinheiro suficiente no banco para cobri-lo. } \\
\text { Q15. Comprei algo para me sentir melhor comigo mesmo. } \\
\text { Q16. Sinto-me ansioso ou nervoso em dias que não vou às compras. } \\
\text { Q17. Paguei apenas o valor mínimo das minhas faturas de cartão de crédito. }\end{array}$ & $\begin{array}{l}3 \text { (Indiferente) } \\
4 \text { (Concordo) } \\
5 \text { (Concordo totalmente) }\end{array}$ \\
\hline
\end{tabular}




\begin{tabular}{|l|l|}
\hline Variáveis de perfil & Alternativas \\
\hline Gênero & 0 (mulheres) ou 1(homens) \\
\hline Possui dependentes & 0 (não) ou 1(sim) \\
\hline Ocupação & 0 (não possui ocupação) ou 1 (possui ocupação) \\
\hline Idade & Quantitativa \\
\hline Escolaridade & $\begin{array}{l}1 \text { (Ensino Fundamental), 2 (Ensino Médio), 3 (Curso Técnico), } 4 \text { (Ensino Superior), } 5 \text { (Especialização ou MBA) e } 6 \text { (Pós- } \\
\text { Graduação Stricto Sensu). }\end{array}$ \\
\hline Renda Mensal Familiar & $\begin{array}{l}1 \text { (Não possuo renda própria), 2 (Até } \mathrm{R} \$ 868,00), 3 \text { (Entre } \mathrm{R} \$ 868,01 \text { e } \mathrm{R} \$ 1.738,00), 4 \text { (Entre } \mathrm{R} \$ 1.738,01 \text { e } \mathrm{R} \$ 2.604,00), \\
\mathrm{R} \$ 7.812,01 \text { e } \mathrm{R} \$ 10.416,00) \text { e } 9 \text { (Mais de } \mathrm{R} \$ 10.416,00) .\end{array}$ \\
\hline
\end{tabular}

Fonte: Elaborado pelos autores.

\section{Análise e discussão dos resultados}

Este capítulo está dividido em três seções: i) apresenta-se o perfil da amostra, bem como o comportamento dos entrevistados referente à propensão ao endividamento e ao comportamento materialista e de compras compulsivas; ii) validação dos fatores materialismo e compras compulsivas; e iii) estima-se a probabilidade de um indivíduo ser mais ou menos propenso ao endividamento, considerando o comportamento materialista e de compras compulsivas, além das variáveis de perfil, a partir do modelo Logit Multinomial.

\subsection{Estatística Descritiva}

O processo de coleta de dados foi realizado na Mesorregião Centro Ocidental Rio-Grandense e ao final da pesquisa foram coletados 2.485 instrumentos válidos, sendo perfil da amostra apresentado na Tabela 3.

Com base nos resultados da Tabela 3, percebe-se que a amostra é bastante heterogênea, apresentando uma idade média de 34,77 anos. Em relação ao gênero, a maioria dos indivíduos pertence ao gênero feminino (57,3\%), em contrapartida aos $42,7 \%$ do gênero masculino. Destaca-se que a maior parcela dos respondentes não possui dependentes $(54,3 \%)$ e concluíram o ensino médio (44,2\%), seguido daqueles que possuem ensino superior $(26,1 \%)$. No que tange à ocupação, verifica-se que a maior parte dos pesquisados são empregados assalariados $(38,3 \%)$ e funcionários públicos (24,8\%). Por fim, ao observar o nível de renda mensal familiar, identifica-se o maior número de indivíduos com renda entre $R \$ 868,01$ e $R \$ 1.738,00$ (20,8\%), seguidos dos que possuem renda familiar entre $\mathrm{R} \$ 1.738,01$ e $\mathrm{R} \$ 2.604,00$ (19,9\%) e daqueles com renda entre $\mathrm{R} \$ 2.604,01$ e $\mathrm{R} \$ 3.472,00$ (17,3\%).

Após a identificação do perfil da amostra, busca-se compreender a propensão ao endividamento e os comportamentos materialista e de compra compulsiva dos indivíduos. As Tabelas 4 e 5 apresentam estes resultados, respectivamente.

Ao analisar a propensão ao endividamento, considerando o nível de gastos em relação ao dinheiro que ganham, 42,6\% dos indivíduos dizem gastar menos do que ganham ou, ainda, gastam igual ao que ganham $(36,5 \%)$, apresentando uma propensão baixa e mediana ao endividamento, respectivamente. Já a menor parcela dos pesquisados afirma gastar mais do que ganha, representando $20,8 \%$ do total de indivíduos analisados. Tal comportamento aponta para uma baixa propensão ao endividamento nos pesquisados, uma vez que mais de $40 \%$ dos indivíduos afirmam gastar menos do que ganham.

No entanto, uma parcela significativa $(36,5 \%)$ aponta uma propensão mediana a endividar-se, quando afirmam gastar o mesmo que ganham, não realizando uma reserva para gastos inesperados, o que pode acarretar em um endividamento futuro. Santos \& Silva (2014) salientam que essa dificuldade financeira em imprevistos acontece pelo fato das famílias não manterem uma reserva financeira para 
imprevistos ou emergência, assim o surgimento de qualquer eventualidade exige a contratação de recursos de terceiros, ou seja, endividar-se para suprir a necessidade emergente. Tal fato é preocupante uma vez que as pessoas endividadas têm pouca ou nenhuma habilidade em lidar com dinheiro e o fato de não conseguirem passar o mês dentro do orçamento, faz com que passem a trabalhar exclusivamente para quitar as dívidas, dificultando a recuperação do equilíbrio econômico (Ferreira, 2006).

Tabela 3. Perfil dos respondentes quanto às variáveis: gênero, possuir dependentes, escolaridade, ocupação e renda mensal familiar

\begin{tabular}{|c|c|c|c|}
\hline & Variáveis & Frequência & Percentual \\
\hline \multirow{2}{*}{ Gênero } & Masculino & 1062 & 42,7 \\
\hline & Feminino & 1423 & 57,3 \\
\hline \multirow{2}{*}{ Possuir Dependentes } & Não & 1332 & 54,3 \\
\hline & Sim & 1122 & 45,7 \\
\hline \multirow{6}{*}{ Escolaridade } & Ensino Fundamental & 265 & 10,9 \\
\hline & Ensino Médio & 1074 & 44,2 \\
\hline & Curso Técnico & 237 & 9,8 \\
\hline & Ensino Superior & 635 & 26,1 \\
\hline & Especialização ou MBA & 155 & 6,4 \\
\hline & Pós-graduação Stricto Sensu & 64 & 2,6 \\
\hline \multirow{8}{*}{ Ocupação } & Funcionário(a) Público(a) & 599 & 24,8 \\
\hline & Empregado(a) Assalariado(a) & 923 & 38,3 \\
\hline & Profissional Liberal & 71 & 2,9 \\
\hline & Autônomo(a) & 251 & 10,4 \\
\hline & Agricultor(a) & 42 & 1,7 \\
\hline & Aposentado(a) & 112 & 4,6 \\
\hline & Não trabalha & 204 & 8,5 \\
\hline & Outro & 211 & 8,7 \\
\hline \multirow{8}{*}{ Renda Mensal Familiar } & Até $\mathrm{R} \$ 868,00$ & 170 & 7,0 \\
\hline & Entre $R \$ 868,01$ e $R \$ 1.738,00$ & 506 & 20,8 \\
\hline & Entre $\mathrm{R} \$ 1.738,01$ e $\mathrm{R} \$ 2.604,00$ & 485 & 19,9 \\
\hline & Entre $R \$ 2.604,01$ e $R \$ 3.472,00$ & 422 & 17,3 \\
\hline & Entre $\mathrm{R} \$ 3.472,01$ e $\mathrm{R} \$ 5.208,00$ & 369 & 15,2 \\
\hline & Entre $\mathrm{R} \$ 5.208,01$ e $\mathrm{R} \$ 7.812,00$ & 195 & 8,0 \\
\hline & Entre $R \$ 7.812,01$ e $R \$ 10.416,00$ & 137 & 5,6 \\
\hline & Mais de $\mathrm{R} \$ 10.416,00$ & 150 & 6,2 \\
\hline
\end{tabular}

Fonte: Elaborada pelos autores, com base nos resultados da pesquisa. 
Tabela 4. Estatística descritiva da propensão ao endividamento

\begin{tabular}{|l|l|c|c|}
\hline \multicolumn{2}{|c|}{ Variáveis } & Frequência & Percentual \\
\hline \multirow{3}{*}{ Q1. Com relação aos seus gastos, você diria que: } & Gasto menos do que ganho (Propensão baixa) & 1053 & 42,6 \\
\cline { 2 - 5 } & Gasto igual ao que ganho (Propensão mediana) & 903 & 36,5 \\
\cline { 2 - 5 } & Gasto mais do que ganho (Propensão alta) & 515 & 20,8 \\
\hline
\end{tabular}

Fonte: Elaborada pelos autores, com base nos resultados da pesquisa.

Tabela 5. Estatísticas descritivas dos fatores materialismo e compras compulsivas

\begin{tabular}{|c|c|c|c|c|c|c|c|c|c|}
\hline \multirow[b]{2}{*}{ Fator } & \multirow[b]{2}{*}{ Variáveis } & \multirow[b]{2}{*}{ Média } & \multirow[b]{2}{*}{ Mediana } & \multirow{2}{*}{$\begin{array}{l}\text { Desvio } \\
\text { Padrão }\end{array}$} & \multicolumn{5}{|c|}{ Percentuais } \\
\hline & & & & & $\begin{array}{l}\text { Discordo } \\
\text { totalmente }\end{array}$ & Discordo & Indiferente & Concordo & $\begin{array}{l}\text { Concordo } \\
\text { totalmente }\end{array}$ \\
\hline \multirow{9}{*}{ 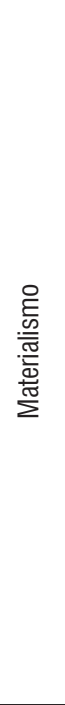 } & $\begin{array}{l}\text { Q2. Eu tento manter uma vida simples, se } \\
\text { consideradas as minhas posses. }\end{array}$ & 3,88 & 4,00 & 0,84 & 1,42 & 6,78 & 13,23 & 59,33 & 19,24 \\
\hline & $\begin{array}{l}\text { Q3. As coisas que possuo dizem muito so- } \\
\text { bre como está a minha vida atualmente. }\end{array}$ & 3,56 & 4,00 & 1,01 & 3,81 & 14,81 & 16,15 & 52,48 & 12,74 \\
\hline & $\begin{array}{l}\text { Q4. Eu gosto de possuir coisas que impres- } \\
\text { sionem as pessoas. }\end{array}$ & 2,00 & 2,00 & 0,96 & 33,46 & 44,08 & 14,20 & 6,02 & 2,24 \\
\hline & $\begin{array}{l}\text { Q5. Eu admiro pessoas que possuem ca- } \\
\text { sas, carros e roupas caras. }\end{array}$ & 2,53 & 2,00 & 1,12 & 21,46 & 28,99 & 28,79 & 16,83 & 3,93 \\
\hline & Q6. Comprar me dá muito prazer. & 3,09 & 3,00 & 1,12 & 10,04 & 20,93 & 26,44 & 34,97 & 7,63 \\
\hline & Q7. Eu gosto de muito luxo em minha vida. & 2,19 & 2,00 & 0,99 & 26,47 & 41,14 & 21,41 & 8,86 & 2,12 \\
\hline & $\begin{array}{l}\text { Q8. Minha vida seria melhor se eu tivesse } \\
\text { algumas coisas que não tenho. }\end{array}$ & 3,10 & 3,00 & 1,14 & 9,71 & 24,12 & 19,63 & 39,05 & 7,49 \\
\hline & $\begin{array}{l}\text { Q9. Eu seria mais feliz se eu pudesse com- } \\
\text { prar mais coisas. }\end{array}$ & 2,84 & 3,00 & 1,13 & 12,09 & 30,75 & 23,98 & 27,10 & 6,09 \\
\hline & $\begin{array}{l}\text { Q10. Às vezes me chateio um pouco por } \\
\text { não poder comprar todas as coisas que eu } \\
\text { gostaria. }\end{array}$ & 3,15 & 3,00 & 1,11 & 8,00 & 24,23 & 18,54 & 42,77 & 6,46 \\
\hline \multirow{7}{*}{ 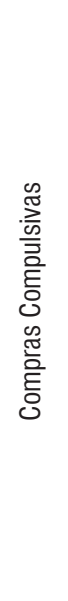 } & $\begin{array}{l}\text { Q11. Se sobra algum dinheiro ao final do } \\
\text { período de pagamento, tenho que gastá-lo. }\end{array}$ & 2,25 & 2,00 & 1,02 & 20,97 & 51,80 & 11,52 & 12,65 & 3,07 \\
\hline & $\begin{array}{l}\text { Q12. Sinto que os outros ficariam horrori- } \\
\text { zados se soubessem dos meus hábitos de } \\
\text { comprar. }\end{array}$ & 2,27 & 2,00 & 1,00 & 21,47 & 45,94 & 20,38 & 8,90 & 3,32 \\
\hline & $\begin{array}{l}\text { Q13. Comprei coisas apesar de não conse- } \\
\text { guir pagar por elas. }\end{array}$ & 1,98 & 2,00 & 0,99 & 33,78 & 47,72 & 6,81 & 9,74 & 1,96 \\
\hline & $\begin{array}{l}\text { Q14. Emiti um cheque quando sabia que não } \\
\text { tinha dinheiro suficiente no banco para cobri-lo. }\end{array}$ & 1,70 & 2,00 & 0,89 & 49,84 & 38,27 & 5,56 & 4,79 & 1,54 \\
\hline & $\begin{array}{l}\text { Q15. Comprei algo para me sentir melhor } \\
\text { comigo mesmo. }\end{array}$ & 2,70 & 2,00 & 1,23 & 19,70 & 31,44 & 13,05 & 31,00 & 4,81 \\
\hline & $\begin{array}{l}\text { Q16. Sinto-me ansioso ou nervoso em dias } \\
\text { que não vou às compras. }\end{array}$ & 1,80 & 2,00 & 0,89 & 43,10 & 40,53 & 10,88 & 4,24 & 1,26 \\
\hline & $\begin{array}{l}\text { Q17. Paguei apenas o valor mínimo das } \\
\text { minhas faturas de cartão de crédito. }\end{array}$ & 1,92 & 2,00 & 1,04 & 42,67 & 35,97 & 10,21 & 8,82 & 2,33 \\
\hline
\end{tabular}

Fonte: Elaborada pelos autores, com base nos resultados da pesquisa. 
Ao analisar as estatísticas descritivas do fator materialismo, percebe-se que as coisas que os respondentes possuem dizem muito sobre como estão as suas vidas atualmente (média 3,56), demonstrando que os bens materiais possuem certa importância. Por outro lado, os indivíduos tentam manter uma vida simples, considerando as suas posses (média 3,88 ), discordam quando indagados a respeito de gostar de possuir coisas que impressionem as pessoas (média 2,00), assim como também não gostam de muito luxo em suas vidas (média 2,19). Resultados semelhantes foram encontrados por Ponchio \& Aranha (2008), que ao investigar 450 pessoas moradoras de nove distritos em São Paulo, chegaram à conclusão de que em média os respondentes não apresentam comportamentos materialistas, embora os bens materiais possuam algum valor.

Já no que tange ao comportamento de compras compulsivas, percebe-se que a maior média foi atribuída à afirmação: "Comprei algo para me sentir melhor comigo mesmo" (média 2,70). Em contrapartida, essa média se deu em virtude do percentual de variabilidade nas respostas, tendo em vista que $31,44 \%$ dos respondentes discordaram desta afirmação e 31,00\% concordaram com a sentença. Em geral, os indivíduos não se mostraram compradores compulsivos, pois discordaram da maioria das afirmações. Uma das questões que se pode destacar é: "Emiti um cheque quando sabia que não tinha dinheiro suficiente no banco para cobrí-lo", considerando que a média foi a mais baixa $(1,70)$, demonstrando que os respondentes não estão dispostos a comprar compulsivamente. Resultados semelhantes podem ser encontrados no estudo realizado por Veludo-de-Oliveira, Ikeda \& Santos (2004), ao concluíram que apenas 7,9\% dos indivíduos foram tidos como compradores compulsivos.

\subsection{Validação dos fatores materialismo e com- pras compulsivas}

Para a validação individual dos fatores materialismo e compras compulsivas utilizou-se a Análise Fatorial Confirmatória (AFC), examinando os relacionamentos entre as variáveis observadas e os seus fatores, realizando a estimação pelo método da máxima verossimilhança. Através das Figuras 1 e 2 exemplifica-se a associação entre as variáveis (manifestas e latentes), demonstrando os coeficientes estimados, enquanto que a Tabela 6 apresenta os índices de ajustes do modelo, sendo eles: estatística qui-quadrado ou relação qui-quadrado/graus de liberdade, GFI, CFI, NFI, TLI, RMR e RMSA.

Inicialmente, fundamentando-se no instrumento de pesquisa desenvolvido por Richins (2004), avaliouse o fator materialismo através de nove questões em uma escala do tipo likert de cinco pontos, sendo que, com exceção da primeira questão (Q2), quanto maior o grau de concordância, mais materialista é o respondente. Já para avaliar a presença de comportamentos de compra compulsiva empregou-se a escala de compra compulsiva desenvolvida originalmente por Faber \& O'Guinn (1992) e adaptada e validada para o Brasil por Leite et al. (2011), a qual é composta por sete questões em uma escala do tipo likert de cinco pontos, sendo que quanto mais os entrevistados concordam com as afirmações, mais comportamento de compra compulsiva eles apresentam. Assim, seguindo as estratégias propostas, inicialmente, ajustou-se o modelo de mensuração dos fatores (Tabela 6).

Para os dois fatores os modelos inicialmente propostos se referem ao modelo com todas as variáveis da escala original. Os resultados indicam que ambos os modelos são inadequados, pois as razões do qui-quadrado/graus de liberdade são superiores ao valor cinco, os índices de ajuste GFI, CFI, NFI e TLI, não atingem o valor mínimo de 0,95 e RMR e RMSEA são superiores a 0,05 e 0,08 , respectivamente. Com isso, na busca de modelos de mensuração adequados, foi adotada a estratégia de retirada das variáveis não significativas e com carga fatorial padronizada que apresentaram valores menores que 0,30 (Hair et al., 2010) e que com isso, não contribuem significativamente para o modelo.

No que tange ao ajuste do fator materialismo, a primeira alteração consistiu na remoção da questão Q3, que não é significativa para o modelo (sig. 0,332). Posteriormente, exclui-se a questão Q2i (coeficiente 0,191) por apresentar um coeficiente padronizado com valor abaixo de 0,30 e com isso, não contribuir significativamente para o modelo. 
Tabela 6. Índices de ajuste dos fatores materialismo e compras compulsivas

\begin{tabular}{|l|c|c|c|c|}
\hline \multirow{2}{*}{\multicolumn{1}{|c|}{ Índices de ajuste }} & \multicolumn{2}{c|}{ Materialismo } & \multicolumn{2}{c|}{ Compras Compulsivas } \\
\cline { 2 - 5 } & Inicial & Final & \multicolumn{2}{c|}{ Inicial } \\
\hline Qui-quadrado (valor) & $1.045,860$ & 13,598 & 216,917 & 8,596 \\
\hline Qui-quadrado (probabilidade) & $p-0,000$ & $p-0,034$ & $p-0,000$ & $p-0,035$ \\
\hline Graus de Liberdade & 27 & 6 & 14 & 3 \\
\hline Qui-quadrado / Graus de Liberdade & 38,736 & 2,266 & 15,494 & 2,865 \\
\hline GFI - Goodness of Fit & 0,898 & 0,998 & 0,975 & 0,999 \\
\hline CFI - Comparative Fit Index & 0,791 & 0,998 & 0,939 & 0,998 \\
\hline NFI - Normed Fit Index & 0,788 & 0,997 & 0,935 & 0,996 \\
\hline TLI- Tucker-Lewis Index & 0,722 & 0,994 & 0,908 & 0,992 \\
\hline RMR - Root Mean Square Residual & 0,078 & 0,012 & 0,040 & 0,009 \\
\hline RMSEA - R. M. S. Error of Approximation & 0,123 & 0,023 & 0,076 & 0,027 \\
\hline Alpha de Cronbach & 0,740 & 0,793 & 0,751 & 0,742 \\
\hline
\end{tabular}

Fonte: Elaborada pelos autores, com base nos resultados da pesquisa.

Em seguida, incluiu-se uma correlação entre "e4" $e$ "e7". Estas questões referem-se a possuir bens, indagando se os respondentes gostam de possuir coisas que impressionam as pessoas (Q4) e, consequentemente, gostam de muito luxo em suas vidas (Q7). Apresentando uma associação $(0,381)$ baixa (entre 0,20 e 0,39), porém muito próxima de ser considerada moderada (entre 0,40 e 0,69), segundo a classificação de Pestana \& Gageiro (2008).

Posteriormente, outra correlação foi inserida entre "e4" e "e5" e entre "e5" e "e7", seguindo o mesmo tema anterior, no entanto relacionando a questão do indivíduo gostar de possuir coisas que impressionem as pessoas (Q4), com isso, admirar pessoas que possuem casas, carros e roupas caras (Q5) e, consequentemente, gostar de muito luxo em sua vida (Q7). Demonstrando associações baixas entre elas $(0,344 e$ 0,298 , respectivamente). A estimação do modelo com esta correlação manteve satisfatórios os coeficientes padronizados das variáveis, no entanto não conseguiu alterar a situação dos índices de ajuste que permaneceram com valores abaixo dos limites exigidos.

Com isso, foi necessária a inclusão de correlações entre "e6" e "e7", "e6" e "e5", "e6" e "e4" e entre "e6" e "e10", no que tange a temática de comprar coisas. Relacionando a questão de o indivíduo considerar que comprar coisas dá muito prazer (Q6) e com isso, gostar de muito luxo em sua vida (Q7); também admirar pessoas que possuem casas, carros e roupas caras (Q5); assim como, gostar de possuir coisas que impressionem as pessoas (Q4) e por fim, às vezes, chatear-se um pouco por não poder comprar todas as coisas que gostaria (Q10). Tais associações apresentaram-se baixas entre "e6" e "e7" $(0,266) e$ entre "e6" e "e5" (0,218), e muito baixas entre "e6" e "e4" $(0,166)$ e entre "e6" e "e10" $(0,127)$.

Após tais modificações, os índices de ajustes apresentaram-se satisfatórios, porém o qui-quadrado permaneceu significativo. Por isso, foi considerado novamente o relatório de modificações, incluindo-se uma última correlação entre os erros das questões Q8 e Q10 ("e8" e "e10"). Pautada no fato do indivíduo considerar que sua vida seria melhor se tivesse algumas coisas que não tem (Q8) e com isso, às vezes, chatear-se um pouco por não poder comprar todas as coisas que gostaria (Q10). Porém, apresentando uma associação muito baixa entre eles $(0,103)$. A inclusão dessa correlação regularizou a situação do qui-quadrado, validando o modelo. 
Assim, ao analisar os índices de ajuste no modelo final do fator materialismo (Tabela 6), confirma-se a adequação e validade do modelo, uma vez que todos os índices de ajuste, confiabilidade e unidimensionalidade calculados apresentaram valores satisfatórios. Além disso, o qui-quadrado deixou de ser significativo ao nível de 3\%, confirmando os ajustes das matrizes estimadas e observadas. A Figura 1 apresenta os modelos de mensuração iniciais e finais do fator materialismo, com os coeficientes padronizados $e$ significância das relações do modelo.

Nota-se que o modelo de mensuração final para o fator materialismo foi formado por sete das nove variáveis originalmente propostas. Sendo que as variáveis Q9 (coeficiente 0,880) e Q8 (coeficiente 0,661 ) são as que mais impactam na propensão do indivíduo apresentar um comportamento materialista, as quais questionavam se os indivíduos seriam mais felizes se pudessem comprar mais coisas e que suas vidas seriam melhores se tivessem algumas coisas que não possuem. Com isso, pode-se perceber que aqueles que concordam com a ideia de possuir mais coisas em suas vidas, tendem a possuir maior propensão a comportarem-se de forma materialista.

Já no que tange ao processo de validação do fator compras compulsivas, como o modelo apresentou todas as variáveis significativas e com coeficientes acima do limite mínimo exigido $(0,30)$ e mesmo assim não apresentou índices de ajuste adequados em seu modelo inicial (Tabela 6), optou-se pela exclusão das variáveis que apresentavam variáveis com os menores coeficientes. Sendo assim, excluiuse a variável Q15 (coeficiente 0,391) e os índices de ajustes continuaram apresentando valores inadequados para o ajuste do modelo. Por isso, optou-se pela exclusão da questão Q12 $(0,485)$, que possuía a menor carga fatorial do modelo. Depois de excluídas tais variáveis, o modelo apresentou índices de ajuste e confiabilidade adequados, mas o quiquadrado permaneceu significativo, o que acabou exigindo a realização de novas modificações.

Figura 1. Modelos de mensuração inicial e final com os coeficientes padronizados e significância das variáveis do fator materialismo

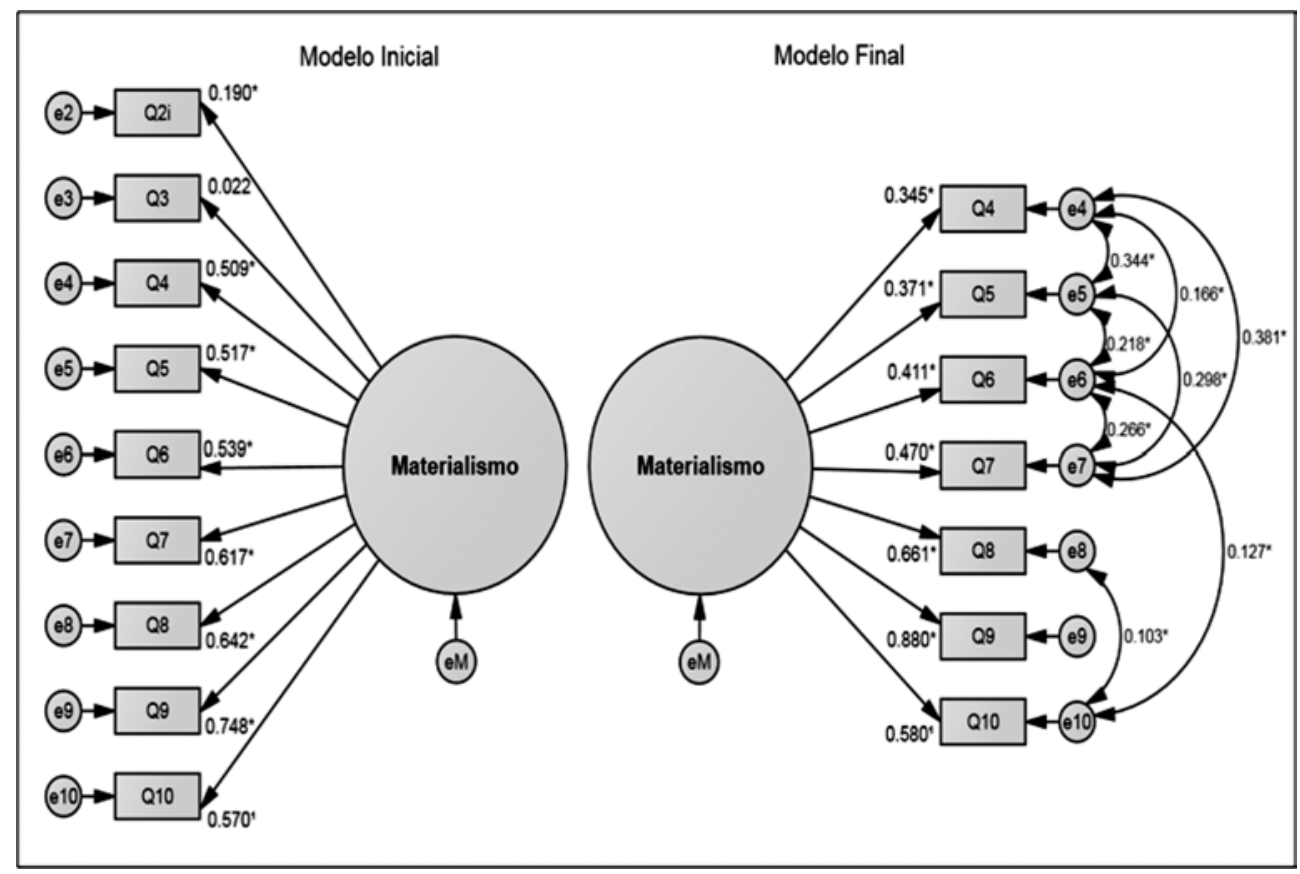

Fonte: Elaborada pelos autores.

Nota: ${ }^{*} p<0,01$. Valor de $z$ não calculado, onde o parâmetro foi fixado em 1 , devido às exigências do modelo. 
Seguindo as recomendações propostas no relatório de modificações do software, inseriu-se uma correlação entre os erros das questões Q11 e Q13 ("e11" e "e13"). A correlação indica a existência de uma relação entre o fato dos indivíduos terem que gastar quando sobra algum dinheiro no final do período de pagamentos (Q11) e comprarem coisas apesar de não conseguir pagar por elas (Q13). Como o modelo continuou mostrando-se não ajustado, foi necessário a inclusão de mais uma correlação entre "e11" e "e16", a qual considera que os indivíduos sentem-se ansiosos ou nervosos em dias que não vão às compras (Q16) e, consequentemente, se sobra algum dinheiro no final do período de pagamentos, eles tem que gastá-lo (Q11). Porém, ambas as correlações apresentaram uma associação muito baixa $(0,156$ e 0,146 , respectivamente).

Com a inclusão desta última correlação regularizou a situação do qui-quadrado, validando o modelo. Uma vez que o modelo final do fator compras compulsivas apresentou índices de ajuste adequados: i) validade convergente, dado que os índices CFI, GFI, NFI e TLI foram superiores a 0,95 e os índices RMR e RMSEA foram inferiores a 0,05 , ii) confiabilidade, tendo em vista que o Alpha de Cronbach foi superior a 0,6 e, iii) unidimensionalidade, dado que o valor de todos os resíduos padronizados foi inferior a 2,58 ( $p<0,05)$. Além disso, o qui-quadrado deixou de ser significativo ao nível de 3\%, confirmando os ajustes das matrizes estimadas e observadas (Tabela 6). A Figura 2 apresenta os modelos de mensuração iniciais e finais do fator compras compulsivas, bem como os coeficientes padronizados e a significância das relações do modelo.

Fazendo um comparativo entre o modelo inicial $e$ o final, nota-se que das sete questões originalmente propostas, cinco integram o modelo de mensuração final do fator compras compulsivas. Além disso, constata-se que as variáveis Q14 (coeficiente 0,688 ) e Q13 (coeficiente 0,673) são as que mais impactam na propensão do indivíduo apresentar um comportamento de compras compulsivas, as quais consideram se os indivíduos emitem cheques mesmo sabendo que não possuem dinheiro suficiente no banco para cobri-lo e que compram coisas apesar de não conseguir pagar por elas. Com isso, pode-se perceber que aqueles que concordam com a ideia de comprar mesmo sabendo que não poderão pagar posteriormente, tendem a possuir maior propensão a ter um comportamento de consumo compulsivo.

Figura 2. Modelos de mensuração inicial e final com os coeficientes padronizados e significância das variáveis do fator compras compulsivas

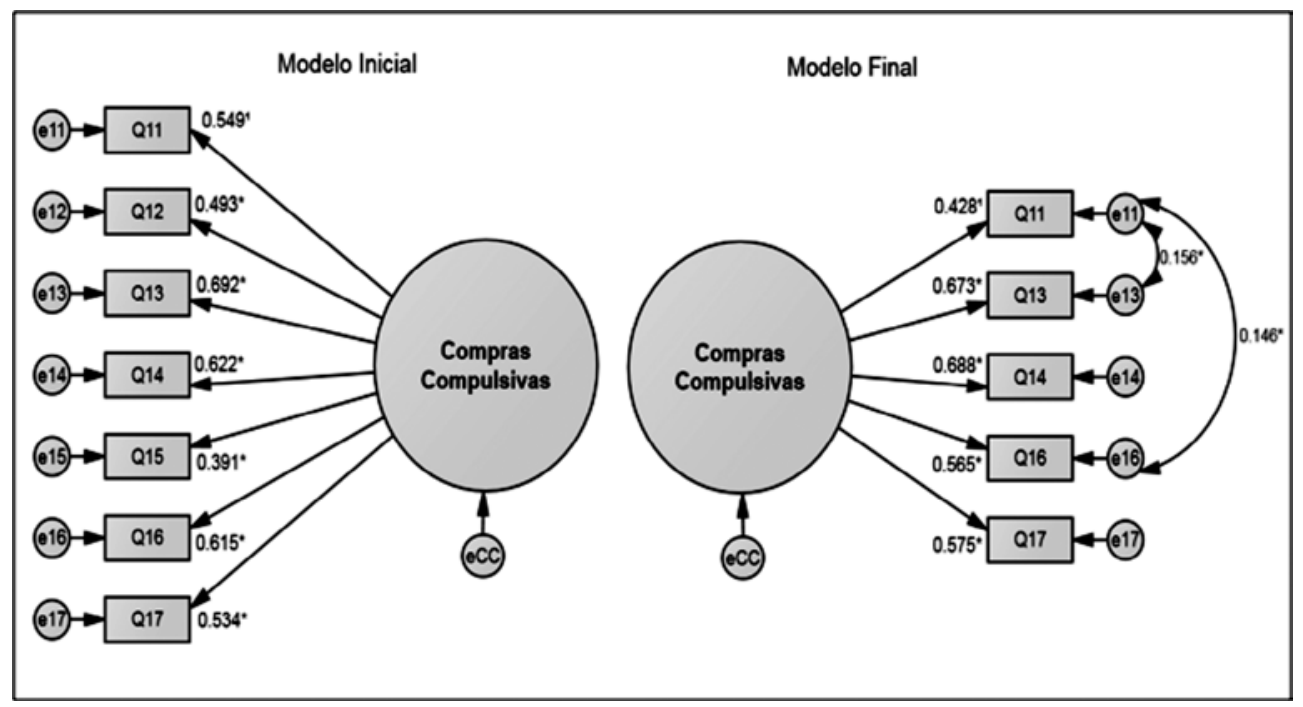

Fonte: Elaborada pelos autores.

Nota: * $p<0,01$. Valor de z não calculado, onde o parâmetro foi fixado em 1 , devido às exigências do modelo. 


\subsection{Modelo Logit Multinomial}

Por fim, buscou-se analisar a influência de fatores comportamentais e das variáveis socioeconômicas e demográficas na propensão ao endividamento dos indivíduos, por meio de um modelo Logit Multinomial. Inicialmente à discussão dos resultados, foram estimados os testes de diagnóstico para ratificar o ajustamento e a robustez do modelo. Os resultados dos testes de Wald e LR são apresentados na Tabela 7.

Tabela 7. Resultados dos testes de Wald e LR

\begin{tabular}{|l|c|c|}
\hline \multicolumn{1}{|c|}{ Variáveis } & $\begin{array}{c}\text { Wald } \\
\text { Qui-Quadrado }\end{array}$ & $\begin{array}{c}\text { Lr } \\
\text { Qui-Quadrado }\end{array}$ \\
\hline \multirow{2}{*}{ Materialismo } & 22,018 & 22,354 \\
& {$[0,008]$} & {$[0,000]$} \\
\hline \multirow{2}{*}{ Compras Compulsivas } & 189,774 & 226,366 \\
& {$[0,000]$} & {$[0,000]$} \\
\hline \multirow{2}{*}{ Dummy Gênero } & 26,676 & 27,054 \\
& {$[0,000]$} & {$[0,000]$} \\
\hline \multirow{2}{*}{ Dummy Dependentes } & 26,027 & 26,642 \\
& {$[0,000]$} & {$[0,000]$} \\
\hline \multirow{2}{*}{ Dummy Ocupação } & 6,101 & 6,088 \\
& {$[0,047]$} & {$[0,048]$} \\
\hline \multirow{2}{*}{ Idade } & 28,608 & 30,304 \\
& {$[0,000]$} & {$[0,000]$} \\
\hline \multirow{2}{*}{ Escolaridade } & 3,337 & 3,340 \\
& {$[0,189]$} & {$[0,188]$} \\
\hline \multirow{2}{*}{ Renda Familiar } & 4,090 & 4,097 \\
& {$[0,129]$} & {$[0,129]$} \\
\hline
\end{tabular}

Fonte: Elaboradapelosautores, combasenosresultados dapesquisa. Nota: [ ] Probabilidade > Qui-Quadrado.

Os resultados obtidos tanto no teste de Wald quando no LR, indicam que todos os coeficientes associados com dada variável são diferentes de zero. Ressalta-se que para as variáveis escolaridade e renda familiar não se rejeitou a hipótese nula, porém a manutenção das variáveis é justificada teoricamente, uma vez que diversos autores apontam que tais variáveis podem influenciar na propensão ao endividamento (Ponchio, 2006; Zerrenner, 2007; Bricker et al., 2012). Além disso, o teste LR corrobora as evidências do teste de Wald, pois a maioria das probabilidades também se mostrou estatisticamente significativa. A fim de corroborar tais resultados, analisaram-se os testes de Wald e LR para comparação de variáveis, utilizados para testar se as combinações entre as variáveis são diferentes de zero (Tabela 8).

Tabela 8. Resultados dos Testes de Wald e LR para comparação de variáveis

\begin{tabular}{|c|c|c|}
\hline $\begin{array}{l}\text { Comparação entre as } \\
\text { categorias }\end{array}$ & $\begin{array}{c}\text { Request } \\
\text { Combine } \\
\text { Qui-Quadrado }\end{array}$ & $\begin{array}{c}\text { Lrcomb } \\
\text { Qui-Quadrado }\end{array}$ \\
\hline $\begin{array}{c}1 \text { - Gasto menos do que ganho } \\
\mathrm{e} \\
2 \text { - Gasto igual ao que ganho }\end{array}$ & $\begin{array}{l}128,459 \\
{[0,000]}\end{array}$ & $\begin{array}{l}144,056 \\
{[0,000]}\end{array}$ \\
\hline $\begin{array}{l}1 \text { - Gasto menos do que ganho } \\
\text { e } \\
3 \text { - Gasto mais do que ganho }\end{array}$ & $\begin{array}{l}315,503 \\
{[0,000]}\end{array}$ & $\begin{array}{c}435,814 \\
{[0,000]}\end{array}$ \\
\hline $\begin{array}{l}2 \text { - Gasto igual ao que ganho } \\
\text { e } \\
3 \text { - Gasto mais do que ganho }\end{array}$ & $\begin{array}{l}125,598 \\
{[0,000]}\end{array}$ & $\begin{array}{l}148,904 \\
{[0,000]}\end{array}$ \\
\hline
\end{tabular}

Fonte: Elaborada pelos autores.

Nota: [ ] Probabilidade > Qui-Quadrado.

Assim, percebe-se que quando as categorias são comparadas entre si, os resultados tanto para o teste de combinação de Wald quanto para o de combinação de LR exibem que todos os coeficientes associados com determinado par de variáveis são iguais a zero, ou seja, as categorias podem ser combinadas, visto que as probabilidades foram significativas a um nível de 1\%. Por fim, para testar a independência das alternativas irrelevantes utilizouse o teste de Small-Hsiao (Tabela 9).

Tabela 9. Resultados do teste de Small-Hsiao

\begin{tabular}{|c|c|}
\hline Alternativas & $\begin{array}{c}\text { Small-Hsiao } \\
\text { Qui-Quadrado }\end{array}$ \\
\hline 2 - Gasto igual ao que ganho & 11,625 \\
& {$[0,235]$} \\
\hline 3 - Gasto mais do que ganho & 3,644 \\
& {$[0,933]$} \\
\hline
\end{tabular}

Fonte: Elaborada pelos autores.

Nota: [ ] Probabilidade > Qui-Quadrado. 
O teste de Small-Hsiao indicou que as razões são independentes das demais alternativas, pela nãorejeição da hipótese nula. Complementariamente, para a adequabilidade do modelo estimado foi realizado o teste de Hosmer-Lemeshow, o qual avalia a qualidade do modelo comparando as frequências observadas $e$ as esperadas. O resultado sugeriu a não rejeição da hipótese nula, indicando que o modelo apresenta ajustamento adequado, o que pressupõe que a variação residual está explicada satisfatoriamente (Qui-Quadrado 9,786 e Probabilidade $0,878)$.
Assim, após a verificação do modelo, desenvolveuse a estimação dos coeficientes. Entretanto, dado que as estimativas obtidas do modelo Logit Multinomial não são de fácil interpretação, pois não representam diretamente as respostas marginais, como encontrado no método tradicional de Mínimos Quadrados Ordinários, optou-se pela análise dos coeficientes marginais de cada variável explicativa com base nos valores médios da amostra. Essa forma de estimação permite calcular os efeitos marginais separadamente para cada alternativa (Tabela 10).

Tabela 10. Efeitos marginais do modelo Logit Multinomial para Propensão ao Endividamento

\begin{tabular}{|c|c|c|c|}
\hline \multirow[b]{2}{*}{ Variáveis } & \multicolumn{3}{|c|}{ Alternativas } \\
\hline & $\begin{array}{l}1 \text { - Gasto menos do que ganho } \\
\text { (Propensão BAIXA) }\end{array}$ & $\begin{array}{l}2 \text { - Gasto igual ao que ganho } \\
\text { (Propensão MEDIANA) }\end{array}$ & $\begin{array}{l}3 \text { - Gasto mais do que ganho } \\
\text { (Propensão ALTA) }\end{array}$ \\
\hline Materialismo & $\begin{array}{c}-0,081^{\star \star *} \\
{[0,017]}\end{array}$ & $\begin{array}{c}0,051^{* * *} \\
{[0,016]}\end{array}$ & $\begin{array}{c}0,030 * * * \\
{[0,012]}\end{array}$ \\
\hline Compras Compulsivas & $\begin{array}{c}-0,223^{* * *} \\
{[0,022]}\end{array}$ & $\begin{array}{l}0,041^{* *} \\
{[0,020]}\end{array}$ & $\begin{array}{c}0,182^{\star * *} \\
{[0,013]}\end{array}$ \\
\hline Dummy Gênero & $\begin{array}{c}-0,114^{* * *} \\
{[0,024]}\end{array}$ & $\begin{array}{l}-0,044^{*} \\
{[0,023]}\end{array}$ & $\begin{array}{c}-0,070 * * * \\
{[0,017]}\end{array}$ \\
\hline Dummy Dependentes & $\begin{array}{c}-0,118^{* * *} \\
{[0,027]}\end{array}$ & $\begin{array}{c}0,030 \mathrm{~ns} \\
{[0,026]}\end{array}$ & $\begin{array}{c}0,088^{\star * \star} \\
{[0,020]}\end{array}$ \\
\hline Dummy Ocupação & $\begin{array}{c}0,036 \mathrm{~ns} \\
{[0,031]}\end{array}$ & $\begin{array}{c}-0,070 * * \\
{[0,030]}\end{array}$ & $\begin{array}{c}0,033 \mathrm{~ns} \\
{[0,021]}\end{array}$ \\
\hline Idade & $\begin{array}{c}0,005^{\star * *} \\
{[0,001]}\end{array}$ & $\begin{array}{c}-0,001 \mathrm{~ns} \\
{[0,001]}\end{array}$ & $\begin{array}{c}-0,003^{* * *} \\
{[0,001]}\end{array}$ \\
\hline Escolaridade & $\begin{array}{l}0,019^{*} \\
{[0,010]}\end{array}$ & $\begin{array}{c}-0,012 \mathrm{~ns} \\
{[0,010]}\end{array}$ & $\begin{array}{c}-0,007 \mathrm{~ns} \\
{[0,007]}\end{array}$ \\
\hline Renda Familiar & $\begin{array}{l}0,014^{* *} \\
{[0,007]}\end{array}$ & $\begin{array}{l}-0,011^{*} \\
{[0,006]}\end{array}$ & $\begin{array}{c}-0,003 \mathrm{~ns} \\
{[0,005]}\end{array}$ \\
\hline $\begin{array}{l}\text { Estatística LR } \\
\text { Probabilidade } \\
\text { Pseudo R } \\
\text { Número observações }\end{array}$ & $\begin{array}{c}465,27 \\
0,000 \\
0,1078 \\
2045\end{array}$ & & \\
\hline
\end{tabular}

Fonte: Elaborada pelos autores.

Nota: ${ }^{* * *} p \leq 0,01 ;{ }^{* *} p \leq 0,05 ;{ }^{*} p \leq 0,10$; ns $p>0,10$; [ ] erro padrão. 
Ao analisar as estimativas dos coeficientes em relação ao fator materialismo, percebe-se que todas são significativas ao nível de $1 \%$, indicando que uma alteração no comportamento materialista pode alterar a probabilidade de o indivíduo tornar-se mais ou menos propenso ao endividamento. $\mathrm{O}$ sinal negativo na primeira alternativa ( 1 - gasto menos do que ganho) aponta que quanto menor for o nível de comportamento materialista, maior será a probabilidade de o respondente gastar menos do que ganha e consequentemente, terá uma propensão baixa ao endividamento. Já o sinal positivo nas demais alternativas ( 2 - gasto igual ao que ganho e 3 - gasto mais do que ganho) ratifica a pressuposição de que pessoas com maiores níveis de comportamento materialista serão menos cautelosas com relação aos seus gastos e, consequentemente, terão uma maior probabilidade de serem propensos a endividar-se.

Especificadamente, o aumento de um nível no comportamento materialista do indivíduo, diminui a probabilidade de ele apresentar uma baixa propensão ao endividamento em 0,081 pontos percentuais, assim como aumenta a probabilidade em 0,051 e 0,030, do indivíduo demonstrar uma propensão mediana e alta ao endividamento, respectivamente. Tais resultados ratificam os encontrados por Ponchio (2006), ao averiguar que quanto maior o nível de materialismo, mais propenso ao endividamento a pessoa será. Assim como Watson (2003) ao detectar que quanto mais materialista for o indivíduo, maior a tendência de ele se auto classificar como gastador e realizar empréstimos para comprar produtos de luxo. Santos \& Souza (2014) também averiguaram por meio de uma regressão logística que, embora haja um consumo expressivo dos jovens universitários, o endividamento financeiro é mais explicado pelo comportamento materialista destes jovens, sendo o fator que mais impactou no endividamento.

No que tange às estimativas em relação ao comportamento de compras compulsivas, nota-se que a alteração neste comportamento pode alterar a probabilidade de o indivíduo tornar-se mais ou menos propenso ao endividamento, uma vez que todas são significativas ao nível de 5\%. Ao analisar os coeficientes, percebe-se que o aumento de um nível no comportamento de compras compulsivas diminui em 0,222 pontos percentuais o fato dele gastar menos do que ganha e consequentemente, apresentar uma baixa propensão a endividar-se. Já os indivíduos que gastam igual ou mais do que ganham, aumentam em 0,041 e 0,182, respectivamente, as chances de endividarem-se ao aumentar um nível no seu comportamento de compradores compulsivos.

Tal achado é ratificado pelos encontrados por Roberts \& Jones (2001), ao detectarem que o comportamento de compra compulsiva de um indivíduo tem como principal consequência a maior propensão ao endividamento. Carvalho \& Alves (2010) também afirmam que a aquisição compulsiva de produtos, maximiza o problema do endividamento, uma vez que possivelmente a pessoa continuará consumindo compulsivamente sem condições financeiras para isso. Neste mesmo panorama, Figueira \& Pereira (2014) realizaram uma análise dos antecedentes do endividamento do consumidor e verificaram que a compra compulsiva influencia positivamente a propensão ao endividamento.

Posteriormente aos fatores comportamentais, busca-se investigar de que maneira as características de perfil interferem na probabilidade de uma pessoa tornar-se mais ou menos propensa a endividar-se. Quanto ao gênero, observa-se uma relação negativa nas três alternativas, essas relações indicam que as mulheres apresentam uma maior probabilidade à baixa propensão ao endividamento, assim como, à propensão mediana $e$ alta. Este resultado vai ao encontro da literatura, uma vez que ainda não foi encontrado um consenso quanto à relação do gêenero com a propensão ao endividamento. Alguns autores constataram que as mulheres endividam-se com menos frequência do que os homens, justificadas pela prudência na hora de tomar as decisões financeiras (Keese, 2010; Wang, Lu \& Malhotra, 2011), já outros verificarem que as mulheres são mais propensas ao endividamento (Vieira et al., 2014), além daqueles que afirmam que as mulheres acabam se endividando mais devido à maior predisposição a incorrer em comportamentos de compra compulsiva (Faber \& O'Guinn, 1992). 
Quanto à variável possuir dependentes, o único coeficiente que não se mostrou significativo foi o correspondente a alternativa da propensão mediana. Já o fato dos indivíduos possuírem dependentes apresenta uma maior probabilidade de apresentarem uma propensão alta ao endividamento. Conforme encontrado por Keese (2010), ao afirmar que as famílias com maior número de crianças obtêm maiores níveis de dívidas do que aquelas que possuem mais adultos. Ao analisar a alternativa dos indivíduos possuírem uma propensão baixa ao endividamento, constata-se que o fato dos mesmos possuírem dependentes diminui em 0,118 pontos percentuais esta possibilidade. Averiguando-se novamente, que aqueles que possuem dependentes são mais propensos a endividarem-se.

Em relação à ocupação, o único coeficiente que se mostrou significativo foi o correspondente a alternativa da propensão mediana. O sinal negativo aponta que indivíduos com ocupação apresentam uma menor probabilidade de apresentarem uma propensão mediana ao endividamento. Este resultado é similar ao encontrado por Vieira, Flores \& Campara (2014), ao detectarem que os indivíduos que não trabalham apresentam maior propensão ao endividamento se comparados com as demais ocupações. No que tange a idade, constata-se que o aumento de um ano de vida aumenta a probabilidade em 0,005 pontos percentuais dos indivíduos gastarem menos do que ganham e com isso, apresentarem uma baixa propensão ao endividamento. Complementariamente, o aumento de um ano de vida, diminui em 0,003 pontos percentuais o fato de demonstrarem uma alta propensão a endividarem-se. Em suma, conclui-se que o individuo ao aumentar sua idade, diminui a propensão a endividar-se. Este resultado é ratificado pela maioria dos estudos, em que as pessoas mais jovens são aquelas mais propensas ao endividamento (Zuckerman \& Kuhlman, 2000; Worthy, Jonkman \& Blinn-Pike, 2010; Vieira, Flores \& Campara, 2014).

Ao analisar os coeficientes relacionados com o nível de escolaridade, percebe-se apenas uma alternativa significativa, aquela relacionada à baixa propensão ao endividamento. Constata-se que o aumento em um nível da escolaridade do indivíduo, aumenta em
0,019 pontos percentuais o fato do mesmo apresentar uma baixa propensão. Ponchio (2006) também encontrou uma relação negativa entre o nível de escolaridade e a propensão ao endividamento, indicando que aqueles com maiores níveis de escolaridade tendem a assumir menores dívidas. Vieira, Flores \& Campara (2014) também concluíram que quanto menor o grau de escolaridade do indivíduo maior é sua tendência ao endividamento.

Por fim, verificando a relação existente entre o nível de renda familiar e a propensão ao endividamento, observa-se que ao aumentar um nível na renda familiar do indivíduo, aumenta em 0,014 pontos percentuais a probabilidade de possuir uma baixa propensão. Assim como, diminui em 0,011 as chances de apresentarem uma propensão mediana ao endividamento. Ratificando o fato daqueles que possuem maiores rendas, apresentarem menor propensão ao endividamento, assim como outros autores averiguaram (Zerrenner, 2007; Bricker et al., 2012; Lucena et al., 2014; Vieira, Flores \& Campara, 2014). Especificadamente, Lucena et al. (2014) encontraram que um dos principais fatores que ocasionam o endividamento dos indivíduos é a baixa renda familiar. Segundo Santos \& Souza (2014), este fato acontece pelas facilidades que são proporcionadas pelas agências e pelas instituições financeiras, pois os produtos de crédito facilitam a utilização do dinheiro e, por consequência, podem ser enquadrados no débito financeiro.

Dentre as variáveis investigadas, o fator compras compulsivas é o que apresenta o maior impacto na propensão ao endividamento, por ser o determinante de maior efeito marginal, além de apresentar sinal negativo $(-0,223)$ no grupo de baixa propensão e positivo $(0,182)$ no grupo de alta, demonstrando que quanto maior o controle do comportamento de compras compulsivas do indivíduo, menor será sua propensão a endividar-se. Tal resultado é corroborado por Muller et al. (2011), os quais verificaram que o comportamento de compra compulsiva faz com que os indivíduos tenham uma preocupação constante com o consumo, e assim, a perda de controle sobre o processo de compra torna-se inerente, o que conduz a um aumento do endividamento. Kyrius, McQueen \& Moulding (2013) corroboram 
com essa linha de pensamento, elucidando que a compra compulsiva pode ser entendida como uma atividade que produz recompensas de curto prazo e consequências negativas, como o endividamento, no longo prazo. Ainda neste sentido, os indivíduos compulsivos tendem a agravar a sua situação financeira e serem endividados, devido a pouca racionalidade em suas compras (Lo \& Harvey, 2011; Brougham et al., 2011).

\section{Considerações finais}

O mercado financeiro vem sofrendo transformações ao longo dos anos e um dos fatores que contribuem neste sentido é a facilidade para obtenção de crédito. Além disso, nota-se que os hábitos de compra mudaram e os brasileiros vivenciam um considerável crescimento da oferta de crédito e um expressivo aumento nos prazos de pagamento. Neste panorama, o presente estudo teve por objetivo analisar a influência de fatores comportamentais e das variáveis socioeconômicas e demográficas na propensão ao endividamento dos indivíduos.

Inicialmente, buscou-se analisar o comportamento dos indivíduos no que tange aos fatores comportamentais investigados e verificou-se que embora os respondentes afirmem que as coisas que possuem dizem muito sobre como estão as suas vidas atualmente, em média os indivíduos não apresentaram comportamentos materialistas, tendo em vista que eles tentem a manter uma vida simples. Além disso, os indivíduos também não se mostraram compradores compulsivos, pois praticamente nunca emitem cheques quando sabem que não tem dinheiro suficiente para cobrir. Tais resultados não eram esperados, uma vez que a maioria dos pesquisados $(52,4 \%)$ apresenta rendas entre $R \$ 1.738,00$ e $R \$$ $5.208,00$ mensais e apenas $27,8 \%$ dos pesquisados possuem uma renda mensal de até $\mathrm{R} \$ 1.738,00$. $\mathrm{O}$ que denota que em sua maioria são indivíduos com bons comportamentos, uma vez que não apresentam níveis baixos de renda para explicar a sua preferência pela manutenção de uma vida simples e sem exageros nas compras.

Posteriormente, validaram-se os fatores materialismo e compras compulsivas e analisou-se a influên- cia destes e das variáveis socioeconômicas e demográficas na propensão ao endividamento dos indivíduos, por meio de um modelo Logit Multinomial. Os principais resultados apontam que quanto menor for o nível de comportamento materialista e de compras compulsivas, maior será a probabilidade de o respondente apresentar uma baixa propensão a endividar-se, além daqueles com maiores níveis apresentarem uma propensão mediana $e$ alta ao endividamento, ratificando a pressuposição de que pessoas com maiores níveis de comportamento materialista e de compras compulsivas serão menos cautelosas com relação aos seus gastos $e$, consequentemente, terão uma maior probabilidade de serem propensos a endividar-se.

Já ao analisar de que maneira as características de perfil interferem na probabilidade de uma pessoa tornar-se mais ou menos propensa a endividar-se, verificou-se que as mulheres apresentam uma maior probabilidade à baixa propensão ao endividamento, mas também à propensão mediana e alta. Além daqueles que possuem dependentes apresentarem uma maior probabilidade de possuírem uma propensão alta ao endividamento. Já os indivíduos que possuem uma ocupação denotam uma menor probabilidade de apresentarem uma propensão mediana ao endividamento. No que tange a idade, constata-se que o aumento de um ano de vida aumenta a probabilidade dos indivíduos possuírem uma baixa propensão a endividarem-se; além do aumento em um ano de vida, diminui a probabilidade de ter uma propensão alta, concluindo-se que o indivíduo ao aumentar sua idade, diminui a propensão a endividar-se. Averigua-se também que o aumento em um nível da escolaridade e da renda familiar do indivíduo, aumenta a chance do mesmo possuir uma propensão baixa ao endividamento. Ainda, verificou-se que entre as variáveis investigadas, o fator compras compulsivas é o que apresenta o maior impacto na propensão ao endividamento, demonstrando que quanto maior o controle do comportamento de compras compulsivas do indivíduo, menor será sua propensão a endividar-se.

Assim, deve-se considerar o endividamento como sendo compreendido a partir da sua multidimensionalidade, o qual pode ser causado por diversos 
aspectos, como fatores econômicos, aspectos psicológicos, fatores comportamentais, entre outros. Especificadamente, neste estudo, averiguou-se que quanto pior for o comportamento materialista $e$ de compras compulsivas do indivíduo, maior será a propensão que o mesmo possui de endividar-se. Assim como, aqueles que possuem dependentes, não possuem uma ocupação, com menores níveis de idade, de escolaridade e de renda familiar são os que apresentam uma maior propensão ao endividamento.

Portanto, a principal contribuição desta pesquisa se refere à conscientização dos agentes financeiros públicos e privados de que a análise do perfil comportamental dos indivíduos deve ser incorporada aos modelos já existentes para uma melhoria da previsão de inadimplência das famílias. Ressalta-se ainda que conforme já demonstrado pela literatura, o descontrole financeiro traz consequências como a marginalização e exclusão social, assim como doenças físicas e mentais, que no futuro podem além de agravar o nível de inadimplência no país, aumentar os gastos para atendimento psicológicos e de saúde pública.

Como limitação, destaca-se a possível omissão de respostas por parte dos pesquisados, visto que as variáveis questionadas abordam aspectos pessoais. Já como sugestões para trabalhos futuros destacamse a realização de pesquisas que investiguem qualitativamente a propensão ao endividamento dos indivíduos, além de realizar a aplicação deste instrumento em outras regiões, a fim de realizar uma comparação com os achados desta pesquisa.

\section{Referências}

Archer, L. K., Lemeshow, S. \& Hosmer, D. W. (2007). Goodnessof-fit for logistic models when data are collected using a complex sampling design. Computacional Statistics \& Data Analysis The Hague, 51 (9): 4450-4464.

Braido, G. M. (2014). Planejamento Financeiro Pessoal dos Alunos de Cursos da Área de Gestão: estudo em uma instituição de ensino superior do Rio Grande do Sul. Estudo \& Debate, 21 (1): 37-58

Bricker, J., Kennickell, A. B., Moore, K. B. \& Sabelhaus, J. (2012). Changes in U.S. family finances from 2007 to 2010: evidence from the Survey of Consumer Finances. Federal Reserve Bulletin, 98 (2): 1-80.
Brougham, R. R., Jacobs-Lawson, J. M., Hershey, D. A. \& Trujillo, K. M. (2011). Who pays your debt? An important question for understanding compulsive buying among American college students. International Journal of Consumer Studies, 35 (1): 79-85.

Brusky, B. \& Magalhães, R. (2006). Assessing Indebtedness: results from pilot survey among steelworkers in Sao Paulo. In: International Labour Office. Disponível em: <http:// www.ilo.org/wcmsp5/groups/public/--ed_emp/documents/ publication/wcms_117961.p df >. Acesso em: $15 \mathrm{fev} .2015$.

Byrne, B. M. (2010). Structural equation modeling with AMOS: Basic concepts, applications, and programming. $2 \mathrm{ed}$. New York: Routledge.

Cameron, A. C. \& Trivedi, P. K. (2009). Microeconometrics using stata. Texas: State Press.

Carvalho, A. A. \& Alves, J. E. D. (2010). As relações entre o consumo das famílias brasileiras, ciclo de vida e gênero. In: XVII Encontro Nacional de Estudos Populacionais, ABEP, Caxambú, MG, Brasil.

Cheung, G. W. \& Lau, R. S. (2008). Testing mediation and suppression effects of latent variables: Bootstrapping with structural equation models. Organizational Research Methods, 11 (2): 296-325.

Confederação Nacional do Comércio de Bens, Serviços e Turismo (CNC). (2014). Pesquisa Nacional de Endividamento e Inadimplência do Consumidor (Peic) - outubro 2014. Disponível em: < http://www.cnc.org.br/sites/default/files/arquivos/ release_peic_outubro_2014.pdf>. Acesso em: 20 fev. 2015.

Dominguez, J. \& Robin, V. (2007). Dinheiro e vida: mude a sua relação com o dinheiro e obtenha a independência financeira. São Paulo: Cultrix.

Faber, R. J. \& O'Guinn, T. C. (1992). A clinical screener for compulsive buying. Journal of Consumer Research, 19 (3): 459-469.

Ferreira, R. (2006). Como Planejar, Organizar e Controlar seu Dinheiro. São Paulo: Thomson IOB.

Figueira, R. F. \& Pereira, R. C. F. (2014). Devo, Não Nego, Pago Quando Puder: uma Análise dos Antecedentes do Endividamento do Consumidor. Revista Brasileira de Marketing - ReMark, 13 (5): 124-138.

Field, A. (2009). Discovering statistics using SPSS. 3 ed. London: Sage

Flores, S. A. M. (2012). Modelagem de equações estruturais aplicada à propensão ao endividamento: uma análise de fatores comportamentais. 192 f. [Dissertação de Mestrado] Administração da Universidade Federal de Santa Maria.

Frade, C., Lopes, C. A., Jesus, F. \& Ferreira, T. (2008). Um perfil dos sobre-endividados em Portugal. Relatório Final. Centro de Estudos Sociais. Faculdade de Economia de Coimbra. Portugal.

Garling, T., Kirchler, E., Lewis, A. \& Van Raaij, F. (2009). Psychology, Financial Decision Making, and Financial Crises. Psychological Science in the Public Interest, 10 (1): 1-47.

Garver, N. S. \& Mentzer, J. T. (1999). Logistics research methods: employing structural equation modeling to test for construct validity. Journal of Business Logistics, 20 (1): 33-57.

Garðarsdóttir, R. B. \& Dittmar. H. (2012). The relationship of materialism to debt and financial well-being: the case of Iceland's perceived prosperity. Journal of Economic Psychology, 33 (6), 471-481. 
Gathergood, J. (2012). Self-control, financial literacy and consumer over-indebtedness. Journal of Economic Psychology, 33 (3), 590-602

Greene, W. H. (2008). Econometric analysis. 6 ed. New Jersey: Pearson Prentice Hall.

Gujarati, D. N. \& Porter, D. C. (2011). Econometria básica. 5 ed. Porto Alegre: Bookman.

Hair, J. R, Black, W. C., Babin, B. J. \& Anderson, R. E. (2010). Multivariate Data Analyses. 7 ed. New Jersey: Pearson.

Hancock, A., Jorgensen, B. \& Swanson, M. (2013). College students and credit card use: the role of parents, work experience, financial knowledge, and credit card attitudes. Journal of Family and Economic Issues, 34 (4): 369-381.

Hooper, D., Coughlan, J. \& Mullen, M. R. (2008). Structural Equation Modeling: Guidelines for Determining Model Fit. The Electronic Journal of Business Research Methods, 6 (1): 53-60.

Instituto Brasileiro de Geografia e Estatística (IBGE). (2010). Censo 2010. Resultados. Disponível em: <http://www.censo2010. ibge.gov.br/resultados_do_censo2010.php>. Acesso em: 21 nov. 2014

Jacoby, M. B. (2002). Does indebtedness influence health? A preliminary inquiry. Journal of Law, Medicine \& Ethics, 30 (4): 560-470.

Keese, M. (2010). Who Feels Constrained by High Debt Burdens? - Subjective vs. Objective Measures of Household Indebtedness. In: Social Sciense Research Network. Disponível em: <http:// papers.ssrn.com/sol3/results.cfm?npage $=2 \&>$. Acesso em: 08 fev. 2015.

Keese, M. \& Schmitz, H. (2011). Broke, ill, and obese: The effect of household debt on health. In: Social Science Research Network. Disponível em: <http://papers.ssrn.com/sol3/ papers.cfm?abs tract_id=1750216> Acesso em: 22 jan. 2015.

Kline, R. B. (2011). Principles and practice of structural equation modeling. 3 ed. New York: The Guilford Press.

Kyrius, M., Mcqueen, P. \& Moulding, R. (2013). Experimental analysis of the relationship between depressed mood and compulsive buying. Journal of Behavior Therapy and Experimental Psychiatry, 44 (1): 194-200.

Koram, L. M., Faber, R. J., Aboujaoude, E., Large, M. D. \& Serpe, R. T. (2006). Estimated prevalence of compulsive buying behavior in the United States. The American Journal of Psychiatry, 163 (10): 1806-1812.

Leite, P. L., Rangé, B. P., Ribas, R. C. Jr., Filomensky, T. Z. \& Oliveira e Silva, A. C. (2011). Tradução e adaptação semântica da Compulsive Buying Scale para o português brasileiro. Jornal Brasileiro de Psiquiatria, 60 (3): 176-181.

Lejoyeux, M. \& Weinstein, A. (2010). Compulsive buying. The American Journal of Drug and Alcohol Abuse, 36 (2): 248-253.

Livingstone, S. M. \& Lunt, P. K. (1992). Predicting personal debt and debt repayment: psychological, social, and economic determinants. Journal of Economic Psychology, 13 (1): 111-134.

Lo, H. \& Harvey, N. (2011). Shopping without pain: Compulsive buying and the effects of credit card availability in Europe and the Far East. Journal of Economic Psychology, 32 (1): 79-92.

Loiola, L. D. P. (2014). O estresse financeiro em dois grupos de profissionais brasileiros. $54 \mathrm{f}$. [Dissertação de Mestrado] Administração de Empresas - Fundação Getulio Vargas, São Paulo.
Lucena, W. G. L. \& Marinho, R. A. L. (2013). Competências financeiras: uma análise das decisões financeiras dos discentes no tocante as finanças pessoais. In: XVI Seminários em Administração, 2013, São Paulo. XVI SEMEAD FEA-USP.

Lucena, W. G. L., Santos, J. M. A., Assis, J. T. \& Santos, M. C. (2014). Fatores que Influenciam o Endividamento e a Inadimplência no Setor Imobiliário da Cidade de Toritama-PE à Luz das Finanças Comportamentais. HOLOS, 6: 90-113.

Lucke, V. A. C., Filipin, R., Brizolla, M. M. B. \& Vieira, E. P. (2014). Comportamento financeiro pessoal: um comparativo entre jovens e adultos de uma cidade da região noroeste do estado do RS. In: Anais dos Seminários em Administração, São Paulo, SP, Brasil, 17.

Moura, A. G. (2005). Impacto dos Diferentes Níveis de Materialismo na Atitude ao Endividamento e no Nível de Dívida para Financiamento do Consumo nas Famílias de Baixa Renda do Município de São Paulo. 174 f. [Dissertação de Mestrado] Administração de Empresas - Escola de Administração de Empresas de São Paulo da Fundação Getulio Vargas, São Paulo.

Muller, K. O. (2010). Sociedade de consumo e cultura do endividamento: estudo de caso sobre compradores compulsivos em Porto Alegre, RS. [Trabalho de conclusão de curso]. Bacharel em Ciências Sociais Universidade Federal do Rio Grande do Sul.

Muller, A., Claes, L., Mitchell, J. E., Faber, R. J., Fischer, J., \& Zwaan, M. (2011). Does compulsive buying differ between male and female students? Personality and Individual Differences, 50 (8): 1309-1312.

Norvilitis, J. M., Merwin, M. M., Osberg, T. M., Roehling, P. V., Young, P. \& Kamas, M. M. (2006). Personality factors, money attitudes, financial knowledge, and credit-card debt in college students. Journal of Applied Social Psychology, 36 (6): 1395-1413.

Norvilitis, J. M., Szablicki, P. B. \& Wilson, S. D. (2003). Factors influencing levels of credit card debt in college students. Journal of Applied Social Psychology, 33 (5): 935-947.

Observatório do Endividamento dos Consumidores. (2002). Endividamento e sobre-endividamento das famílias: conceitos e estatísticas para sua avaliação. Centro de Estudos Sociais da Faculdade de Economia da Universidade de Coimbra, Fev/2002.

O'Guinn, T. C. \& Faber, R. J. (1989). Compulsive Buying: A Phenomenological Exploration. Journal of Consumer Research, 16 (2): 147-157

Pestana, M. H. \& Gageiro, J. N. (2008). Análise de dados para Ciências Sociais: a complementaridade do SPSS. 5 ed. Lisboa: Edições Sílabo.

Plagnol, A. C. (2011). Financial satisfaction over the life course: the influence of assets and liabilities. Journal of Economic Psychology, 32 (1): 45-64.

Ponchio, M. C. (2006). The Influence of Materialism on Consumption Indebtedness in the Context of Low Income Consumers from the City of São Paulo. 175 p. [Tese de Doutorado]. Escola de Administração de Empresas de São Paulo da Fundação Getúlio Vargas: São Paulo.

Ponchio, M. C. \& Aranha, F. (2008). Materialism as a predictor variable of low income consumer behavior when entering into installment plan agreements. Journal of Consumer Behaviour, 7 (1): 21-34. 
Reifner, U., Niemi-Kiesiläinen, J., Huls, N. \& Springeneer, H. (2010). Overindebtedness in European Consumer Law: Principles from 15 European States. Norderstedt: Books on Demand GmbH 2010.

Richins, M. L. (2004). The material values scale: measurement properties and development of a short form. Journal of Consumer Research, 31 (1): 209-219.

Richins, M. L. (2011). Materialism, transformation expectations, and spending: implications forcredit use. Journal of Public Policy \& Marketing, 30 (2): 141-156.

Richins, M. L. \& Dawson, S. (1992). A Consumer Values Orientation for Materialism and Its Measurement: Scale Development and Validation. Journal of Consumer Research, 19 (3): 303-316.

Roberts, J. A. \& Jones, E. (2001). Money attitudes, credit card use, and compulsive buying among American college students. The Journal of Consumer Affairs, 35 (2): 213-240.

Santos, C. P. \& Fernandes, D. V. H. (2011). A socialização de consumo e a formação do materialismo entre os adolescentes. Revista de Administração Mackenzie, 12 (1): 169-203.

Santos, A. C. \& Silva, M. (2014). Importância do planejamento financeiro no processo de controle do endividamento familiar: um estudo de caso nas regiões metropolitanas da Bahia e Sergipe. Revista Formadores: Vivências e Estudos, 7 (1): 05-17.

Santos, T. \& Souza, M. J. B. (2014). Fatores que Influenciam o Endividamento de Consumidores Jovens. Revista Alcance, 21 (1): 152-180.

Sevim, N., Temizel, F. \& Sayilir, O. (2012). The effects of financial literacy on the borrowing behavior of Turkish financial consumers. International Journal of Consumer Studies, 36 (5): 573-579.

Slomp, J. Z. F. (2008). Endividamento e consumo. Revista Relações de Consumo, (108), 109-131.

Trindade, L. L. (2009). Determinantes da Propensão ao Endividamento: um Estudo nas Mulheres da Mesorregião Centro Ocidental Rio-Grandense. 101f. [Dissertação de Mestrado] Universidade Federal de Santa Maria. Programa de Pós Graduação em Administração, Santa Maria.
Trindade, L. L., Righi, M. B. \& Vieira, K. M. (2012). De onde vem o endividamento feminino? Construção e Validação de um modelo PLS-PM. Revista Eletrônica de Administração, 73 (3): 718-746.

Veludo-De-Oliveira, T. M., Ikeda, A. A. \& Santos, R. C. (2004). Compra compulsiva e a influência do cartão de crédito. ERA 44 (3): 89-99.

Vieira, K. M., Flores, S. A. M. \& Campara, J. P. (2014). Propensão ao Endividamento no Município de Santa Maria (RS): Verificando Diferenças em Variáveis Demográficas e Culturais. Teoria e Prática em Administração, 4 (2): 180-205.

Vieira, K. M., Flores, S. A. M., Kunkel, F. R., Campara, J. P. \& Paraboni, A. L. (2014). Níveis de Materialismo e Endividamento: Uma Análise de Fatores Socioeconômicos na Mesorregião Central do Estado no Rio Grande Do Sul. RACEF - Revista de Administração, Contabilidade e Economia da Fundace, 10: $1-20$.

Wang, L. B., Lu, A. W. \& Malhotra, N. K. (2011). Demographics, attitude, personality and credit card features correlate with credit card debt: a view from China. Journal of Economic Psychology, 32 (1): 179-193.

Watson, J. J. (2003). The relationship of materialism to spending tendencies, saving, and debt. Journal of Economic Psychology, 24 (6): 723-739.

Worthy, S. L., Jonkman, J. \& Blinn-Pike, L. (2010). Sensationseeking, risk-taking, and problematic financial behaviors of college students. Journal of Family and Economic Issues, 31 (2): 161-170.

Zerrenner, S. A. (2007). Estudo sobre as razões para o endividamento da população de baixa renda. [Dissertação de Mestrado] Administração. Faculdade de Economia, Administração e Contabilidade - FEA/USP. São Paulo.

Zuckerman, M. \& Kuhlman, D. M. (2000). Personality and risktaking: Common biosocial factors. Journal of Personality, 68 (6): 999-1029. 